NBER WORKING PAPER SERIES

\title{
DO INVESTMENTS IN UNIVERSAL EARLY EDUCATION PAY OFF? LONG-TERM EFFECTS OF INTRODUCING KINDERGARTENS INTO PUBLIC SCHOOLS
}

\author{
Elizabeth U. Cascio \\ Working Paper 14951 \\ http://www.nber.org/papers/w14951 \\ NATIONAL BUREAU OF ECONOMIC RESEARCH \\ 1050 Massachusetts Avenue \\ Cambridge, MA 02138
}

May 2009

I am grateful for funding support from a Spencer Dissertation Fellowship and the University of California, Berkeley, and the comments of numerous seminar participants, most recently at Dartmouth College, Harvard University, and the University of California, Davis. I am particularly thankful to my dissertation advisor, David Card, and to Nora Gordon, Ethan Lewis, and Sarah Reber for helpful discussions and suggestions., The views expressed herein are those of the author(s) and do not necessarily reflect the views of the National Bureau of Economic Research.

NBER working papers are circulated for discussion and comment purposes. They have not been peerreviewed or been subject to the review by the NBER Board of Directors that accompanies official NBER publications.

(C) 2009 by Elizabeth U. Cascio. All rights reserved. Short sections of text, not to exceed two paragraphs, may be quoted without explicit permission provided that full credit, including $\bigcirc$ notice, is given to the source. 
Do Investments in Universal Early Education Pay Off? Long-term Effects of Introducing Kindergartens into Public Schools

Elizabeth U. Cascio

NBER Working Paper No. 14951

May 2009

JEL No. H75,I28,J15,J24

\begin{abstract}
In the 1960s and 1970s, many states introduced grants for school districts offering kindergarten programs. This paper exploits the staggered timing of these initiatives to estimate the long-term effects of a large public investment in universal early education. I find that white children aged five after the typical state reform were less likely to be high school dropouts and had lower institutionalization rates as adults. I rule out similar positive effects for blacks, despite comparable increases in their enrollment in public kindergartens in response to the initiatives. The explanation for this finding that receives most empirical support is that state funding for kindergarten crowded out participation in federally-funded early education among the poorest five year olds.
\end{abstract}

Elizabeth U. Cascio

Department of Economics

Dartmouth College

6106 Rockefeller Hall

Hanover, NH 03755

and NBER

elizabeth.u.cascio@dartmouth.edu 


\section{INTRODUCTION}

More than four decades after the first model preschool intervention, there is an emerging consensus that early childhood education improves a child's economic and social outcomes over the long term. ${ }^{1}$ In light of findings from the Perry Preschool Project and subsequent experiments, early education for disadvantaged children in particular has recently been referred to as a "rare public policy with no equity-efficiency tradeoff" (Heckman and Masterov, 2007; p. 1). Yet, how public funds would best be mobilized to close socioeconomic gaps in preschool access is unclear. Some advocate partial expansions of existing programs that target disadvantaged children, such as the federal Head Start program. Others consider the perennial under-funding of programs like Head Start as evidence of a lack of political will, and argue that universal access is needed to ensure public support.

Existing research provides little insight into the relative merits of universal programs over the long term. While there have been several recent studies of the short-term effects for children of universal education and childcare both in the United States (Gormley and Gayer, 2005) and abroad (Baker, Gruber, and Milligan, 2008; Berlinski, Galiani, and Gertler, 2009), there is no evidence to date on their long-term effects. Head Start has been found to have lasting impacts on criminal behavior and educational attainment (Garces, Currie, and Thomas, 2002; Ludwig and Miller, 2007), but its target population is a group for which the alternative to treatment is almost certainly of lower quality, and the treatment itself much more intensive than that of a universal program. Introducing a universal program may also have general equilibrium effects that expansions of Head Start or state-funded preschool programs for disadvantaged children are too small to bring about.

${ }^{1}$ For reviews of the findings of model preschool interventions, see Karoly, et al. (1997), Barnett (1998), Currie (2001), and Blau and Currie (2006). 
This paper examines the consequences of a series of state interventions to introduce kindergartens into public schools. In the 1960s and 1970s, many states, particularly in the Southern and Western parts of the country, for the first time began offering grants to school districts operating kindergarten programs. Heavy reliance of school revenues on state support in these states and strong latent demand combined to generate quick take-up of these new funds. This is suggested by Figure I, which plots trends in the fraction of school districts with kindergarten programs and the ratio of kindergarten to first grade enrollment in these "treated" states and elsewhere in the country. My formal empirical analysis implies that within only two years of state funding, school districts in the typical state were 21 percentage points more likely to offer kindergarten and public school kindergarten enrollment rates 33 percentage points higher. These interventions present an unusual opportunity to estimate the long-term effects of a large state investment in universal preschool education.

My identification strategy takes advantage of the staggered timing of the funding initiatives across treated states, along with the fact that children attend kindergarten at age five. In my preferred specification, I allow for trends in outcomes in years around the funding initiatives and control flexibly for other potential shocks to a cohort's well-being, interacting cohort dummies with indicators for narrowly-defined groups of treated states. Using data from the four Decennial Censuses spanning 1970 to 2000, I find that white children aged five after the typical state reform were 2.5 percent less likely to be high school dropouts and 22 percent less likely to be institutionalized as adults. I rule out positive effects of the same magnitude for these outcomes for blacks, despite comparable increases in their enrollment in public kindergartens after the initiatives. I also detect no significant impacts of the funding initiatives on other outcomes targeted by state policymakers, such as grade retention, public assistance receipt, employment, and earnings. These findings are robust to a number of specification checks. 
The general lack of a positive program effect is consistent with the low-intensity nature of kindergarten as an early intervention. Potentially more puzzling, however, is the lack of any positive effect for blacks, for whom the funding initiatives had a relatively large effect on overall school enrollment at age five. There are a number of potential explanations for this finding, all of which are unique to an expansion of universal early education. The explanation that receives the most empirical support is that state funding for kindergartens crowded out participation in federally-funded early education among the poorest five year olds - Head Start in particular. I uncover no support for the hypothesis that school districts failing to supplement the state grants placed black students in lower-quality programs, either in kindergarten or in later grades. I also detect no evidence that the establishment of kindergartens as a result of the funding initiatives prompted an increase in academic expectations of students in the early grades, which would have adversely affected children at the bottom of the achievement distribution. Because the data available to distinguish between these hypotheses are not ideal, however, these conclusions must be viewed with caution.

The unique historical context also suggests caution in generalizing from these findings. At the same time, however, the current body of knowledge on long-term effects of early education is derived from participation in programs of roughly the same vintage as that studied here. Indeed, the funding initiatives were passed after the federal government introduced Head Start - a program that continues to be a key alternative to universal preschool for disadvantaged children today. When viewed in this light, my findings raise the possibility that state investments in universal education for children under age five may have some positive effects, but the availability of higher-quality alternatives may make their long-term and reduced-form impacts less than reformers may hope. 
The paper proceeds as follows. The next section discusses the legislative history and goals of state funding for kindergartens. Section III describes the empirical strategy motivated by the funding initiatives. In Section IV, I present findings for kindergarten provision and kindergarten enrollment, and Section V presents estimates the funding initiatives' longer-term effects. Section VI explores the empirical relevance of the alternative hypotheses for the findings, and Section VIII concludes.

\section{The Program}

\section{II.A. Legislative History}

Most state governments have only recently introduced state grants for school districts operating kindergarten programs. Kindergartens began outside of the public school system, funded largely through philanthropic organizations or private tuition. Over the first half of the twentieth century, kindergartens slowly became incorporated into urban schools, at the same time gaining partial funding through local tax revenues (Beatty, 1995; Dean, 1960). By as late as the mid-1960s, however, only 26 states and the District of Columbia made contributions for kindergarten (U.S. Department of Health, Education, and Welfare, 1963a, 1963b, 1967; Tanner and Tanner, 1973).

There were remarkable changes over the next decade: between 1966 and 1975, 19 states began funding kindergartens for the first time. The vast majority of these states were in the South, but the West was well represented as well. Table I gives more detail on the timing of these and later changes, showing, by state, the year of the earliest reform that in principle made funds for kindergarten available to all districts. ${ }^{2}$ In only a few instances did a mandate for local kindergarten programs accompany or follow closely upon establishment of state aid; ${ }^{3}$ response

\footnotetext{
2 Measures of state support for kindergarten were drawn from a variety of sources. See the Appendix.
}

${ }^{3}$ These states are Maryland, Virginia, Oklahoma, West Virginia, and Georgia. 
was at local discretion. By the late 1970s, only two states-Mississippi and North Dakota—did not fund kindergarten programs.

State funding was channeled to districts in two ways. In some cases, kindergarten was incorporated into foundation programs, which promised financial support for kindergartens on an equal basis with support for all other grades in a state's public school system: for each kindergarten class operated, a district was entitled to funding to offset instructional expenses like teachers' salaries. The remaining states channeled funds to districts through appropriations outside of the foundation program. This method of finance made state funding more vulnerable to budget cuts, though all states eventually made kindergarten a part of the basic state school program.

I restrict my analysis to states passing initiatives after 1960 because information on the public/private breakdown of school enrollment is not available prior to the 1960 Census, and data on provision of kindergartens were only systematically collected starting in 1962 . Without such data, it is impossible to demonstrate how earlier initiatives affected the provision of kindergarten programs and substitution across different types of educational activities among five year olds. Doing so is important for interpreting the findings. First, school districts in nontreated states relied less on state funding, suggesting that, if estimable, the "first stage" effects of earlier initiatives would be much weaker. During the 1959-60 academic year, for example, the contribution to school revenues of the median state with an initiative prior to 1960 was only 27.7 percent; among states passing initiatives after 1960, by contrast, this figure was 47.9 percent, and in Southern treated states was even higher, at 52.8 percent. ${ }^{4}$ Second, there were few educational alternatives to public school kindergarten for five year olds prior to 1960. By contrast, the mid1960s witnessed the introduction of two federal programs - Head Start and Title I of the

\footnotetext{
${ }^{4}$ These calculations are based on the school revenue data described in the Appendix. For 1959-60, average state
} contributions to total school revenues for non-treated and treated states were 32.2 and 46.4 percent, respectively. 
Elementary and Secondary Education Act of 1965 - that continue to offer preschool education

for disadvantaged children today. Using variation from earlier initiatives would thus severely

limit the ability to generalize from this study's findings to the current policy environment.

\section{II.B Goals of State Funding for Kindergarten}

Though the initiatives were introduced during a period of rising labor force participation among women with young children, their stated purpose was not to provide subsidized childcare, but rather to improve children's educational outcomes. ${ }^{5}$ The most pressing concern of policymakers was the high cost of "re-educating" children who failed early elementary grades. ${ }^{6}$ Kindergarten funding was also justified on the grounds that it would promote the fiscal health of the state over the longer term. Contemporaries consistently cited the relationship between failure in early grades and the likelihood of dropping out of high school, and some went as far as reason that a reduction in high school dropout would lower incarceration rates and welfare caseloads. ${ }^{7}$

Whether state funding of kindergartens was capable of achieving these goals is open to question. State grants would have been inadequate to cover the costs of operating a kindergarten program on par with those in later grades, suggesting that, if additional funds were not raised from other sources, any positive effects of attendance may have been at least partially offset by

\footnotetext{
${ }^{5}$ If anything, the fact that kindergartens provided free child care was likely to have been an impediment to state funding. For example, Governor Jimmy Carter's attempt to implement state funding for kindergartens in Georgia in the early 1970s was met with great resistance in the state legislature, where detractors charged that it was "babysitting" and "socialistic" (Forgione, 1977; p. 151). In practice, the state funding initiatives did not affect the employment of married mothers, but did raise labor supply among single mothers whose youngest children were aged five (Cascio, 2009).

6 This was evidenced in materials that state departments of education distributed to school districts (e.g., Alabama Department of Education (1977)), as well as by the fact some states, such as North Carolina and Kentucky, deemed their pilot kindergarten programs a success if found to reduce repetition in early grades (Murray, 1973; Jones, 1977). It was also evidenced in legislative language; for example, North Carolina's funding act referred to kindergarten as an "essential prerequisite to success in the first grade and the early years of formal education" (Session Laws of North Carolina, Chapter 603).

7 These broader goals of the funding movement were summarized by the Education Commission of the States in a 1971 report, which claimed that, "To the extent that an educational program for young children contributes to their success as students and citizens, it will significantly reduce subsequent remedial, counseling and even penal and welfare costs...In fact, early childhood programs can be considered integrally related to overall state economic development" (as quoted in Alabama Department of Education, 1977, p. 1).
} 
negative effects of cutbacks in other school programs. Kindergartens have also historically maintained a curriculum focused more on children's social development and less on academic training. ${ }^{8}$ While a focus on socialization does not preclude long-term effects, kindergartens lacked features of targeted early interventions - such as parental involvement and health services - that may be critical to their success. Further, the curriculum of subsequent grades may have become more difficult as kindergartens became an established part of public schooling. ${ }^{9}$

State-funded kindergartens may also have crowded out enrollment in private kindergartens and in compensatory and arguably higher quality educational programs for five year olds funded through Head Start and Title I. The federal effort to bring Head Start to the poorest parts of the South was substantial and persisted through the 1970s (Ludwig and Miller, 2007). While today Head Start primarily serves three and four year olds, a crafter of the program recently recalled that, “... many states did not yet have kindergartens... so the program served a good many five-year-olds," (Zigler and Muenchow, 1992; p. 220). ${ }^{10}$ Even as late as the 1979 fiscal year, 21 percent $(81,375)$ of Head Start enrollees nationwide were five or six years old (U. S. Department of Health, Education, and Welfare, 1980b). ${ }^{11}$ The South was also due roughly half of entitlements under Title I in the mid-1960s (U.S. Senate, 1965) and many public school kindergartens in operation in the South at this time were Title I funded. ${ }^{12}$

\footnotetext{
${ }^{8}$ In the early 1960s, for example, promotion of social development was viewed by most teachers as the main value of kindergarten, and the typical schedule for a kindergarten class included "play time," songs, snacks, naps, outdoor play, and story time, but little structured time learning to count and read (National Education Association, 1962).

9 The kindergarten curriculum today is more focused on acquisition of reading and arithmetic skills (West, Denton, and Germino-Hausken, 2000).

${ }^{10}$ See also the accounts of kindergarten implementation in North Carolina (Murray, 1973), Alabama (Chapman, 1975), and Georgia (Forgione, 1977), which describe both programs as providing early education for five year olds in the absence of state-funded kindergartens.

${ }^{11}$ Twenty percent of enrollees $(77,500)$ were five years old. To the best of my knowledge, this is the first year in which Head Start enrollment by age is reported by the federal government. This figure declined steeply over the next decade: by the 1989 fiscal year, only 36,078 Head Start enrollees (8 percent) were five or six years old (U.S. Department of Health and Human Services, 1990). During the 2007 fiscal year, only 27,252 Head Start enrollees (3 percent) were in this age range (U.S. Department of Health and Human Services, 2008).

${ }^{12}$ During the 1966-67 academic year, for example, 68 percent of reported public school kindergartners in the South were participating in Title I programs (U.S. Department of Health, Education, and Welfare, 1968).
} 
Through any or all of these channels - the resource allocation decisions of school districts, the relatively low-intensity curriculum, increasing difficulty of subsequent grades, and the availability of potentially higher-quality alternatives - the effects of attending a universal early education program may be substantially smaller than those of the more intensive, targeted preschool programs that have been the focus of the literature to date. My analysis therefore estimates the reduced-form effects of kindergarten funding on the outcomes targeted by reformers - not the effects of public school kindergarten attendance - and investigates the empirical relevance of potential mediating factors. Because the alternatives to enrollment in a public school kindergarten, the quality of kindergarten and other school programs attended, and the impacts of curricular change may have differed by family background, I also stratify the analysis by race - a strong correlate of childhood poverty that can be consistently observed across data sets.

\section{EMPIRICAL APPROACH}

My empirical strategy takes advantage of the staggered introduction of state funding for kindergarten from the 1960s forward, shown in Table I, combined with the fact that children generally attend kindergarten at age five. I begin with an event-study model:

$$
y_{s t r g}=\sum_{k=-m}^{l} \theta^{k} D_{s t}^{k}+\lambda_{s}+\delta_{t g}+\gamma_{t r}+\varepsilon_{s t r g}
$$

where $y$ represents an average outcome (e.g., high school dropout rate) among individuals born in

state $s$ and turning five in year $t$, and the vector $\left\{D_{s t}^{k} ; k=-m, \ldots, l\right\}$ consists of a series of dummy variables for year aged five relative to $t_{s}^{*}$, the year of the initiative in state $s$ :

$$
D_{s t}^{k}= \begin{cases}1\left(t-t_{s}^{*} \leq-k\right) & \text { if } k=-m \\ 1\left(t-t_{s}^{*}=k\right) & \text { if }-m<k<l \\ 1\left(t-t_{s}^{*} \geq k\right) & \text { if } k=l\end{cases}
$$


In practice, I let $m=l=7$ and omit $D_{s t}^{-1}$ so that the model is identified. The coefficients of interest are in the vector $\left\{\theta^{k} ; k=-m, \ldots, l\right\}$; for any $k$ such that $-m<k<1, \theta^{k}$ gives the expected difference in outcomes between individuals aged five $k$ years before or after the initiative relative to individuals five years old the year prior to it.

For least squares estimates of $\theta^{k}$ to be unbiased, it must be the case that the timing of the state funding initiatives is uncorrelated with unobserved determinants of outcomes. To reduce bias, I limit the estimation sample to individuals born in states that passed funding initiatives after 1960, since individuals from states passing earlier initiatives are arguably too different to provide for a credible comparison group. In addition to this sample restriction, I interact cohort indicators in equation (1) with dummies for three groups of treated states (indexed by $g$ ) defined on the basis of average education expenditure per pupil in the early 1960s (the vector of fixed effects $\delta_{t g}$ ). There is a strong negative correlation between state spending on education and the year of first state kindergarten funding (Appendix Figure I), suggesting that, if they exist, differential inter-cohort trends across states with different pre-existing levels of commitment to public education would otherwise seriously bias the estimates. ${ }^{13}$ The specification also includes a vector of birth cohort-by-region of birth (indexed by $r$ ) fixed effects $\left(\gamma_{t r}\right)$ to account for different trends in outcomes among individuals born in treated states in the South relative to the rest of the country. These fixed effects are also potentially quite important, given that factors besides the introduction of kindergarten funding - school desegregation in particular - may have differentially affected outcomes for the Southern-born among the cohorts

\footnotetext{
13 The three groups are defined as those with 1964-65 expenditure per pupil (in 2007 dollars) greater than or equal to $\$ 1800$ and less than $\$ 2400$ (Alabama, Arkansas, Georgia, Idaho, Kentucky, Mississippi, North Carolina, South Carolina, Tennessee, and West Virginia), greater than or equal to $\$ 2400$ and less than $\$ 3000$ (Florida, New Hampshire, North Dakota, Oklahoma, Texas, Virginia), and greater than $\$ 3000$ (Alaska, Arizona, Delaware, Maryland, Missouri, Montana, North Dakota, Oregon). The groups were defined so as to be based on three equal ranges (of \$600) for treated Southern states.
} 
of interest (Ashenfelter, Collins, and Yoon, 2006; Reber, 2007). $\lambda_{s}$ is a vector of fixed effects to capture persistent differences in outcomes across individuals born in different states.

The standard approach to summarizing event-study findings is to estimate a differencesin-differences model, which imposes the restrictions on (1) that $\theta^{k}=0$ for all $k<0$ and that $\theta^{k}$ is constant for $k \geq 0$. Estimation of (1) nevertheless reveals significant pre- and/or postinitiative trends in some outcomes, suggesting that a standard differences-in-differences model would yield biased estimates of the average effect of introducing state funding for kindergarten. I therefore turn to a modified version of this model that permits a linear trend in year aged five relative to the initiative, $t-t_{s}^{*}$, and a break in this trend at $t=t_{s}^{*}$ :

$$
\begin{aligned}
y_{s t r g}=\theta D_{s t}+\theta_{1}\left(t-t_{s}^{*}\right) & +\theta_{2}\left(t-t_{s}^{*}\right) \cdot D_{s t} \\
& +\theta^{-m} D_{s t}^{-m}+\theta^{l} D_{s t}^{l}+\lambda_{s}+\delta_{t g}+\gamma_{t r}+\varepsilon_{s t r g}
\end{aligned},
$$

where $D_{s t}=1\left(t-t_{s}^{*} \geq 0\right)$, and all other variables and parameters are defined as above. ${ }^{14}$ The parameter $\theta$ is the predicted effect of the average state funding initiative. ${ }^{15}$

Estimation of equation (3) is subject to the same potential biases as estimation of equation (1). I test the robustness of the summary predictions from (3) in a number of ways. For example, while the identifying assumption cannot be formally tested, it is possible to test whether $D_{s t}$ is uncorrelated with observable cohort characteristics that might affect outcomes under consideration - like measures of average family background - conditional on the controls already in specification (3). I also explore even less restrictive ways to remove birth state-specific cohort trends, as well as estimate models analogous to (3) under the assumption that the

\footnotetext{
${ }^{14}$ Inclusion of the dummies $D_{s t}^{-m}$ and $D_{s t}^{l}$ means that the coefficients $\theta_{1}$ and $\theta_{2}$ are identified from variation in outcomes across birth cohorts $t$ such that $-m<t-t_{s}^{*}<l$. I retain other birth cohorts in the estimation sample to obtain more precise estimates of the cohort fixed effects $\delta_{\operatorname{tg}}$ and $\gamma_{t r}$.

15 While both $\theta^{1}$ (from equation (1)) and $\theta$ (from equation (3)) give the predicted gap in outcomes between individuals turning five the year of the initiative and those five years old the year prior, they are fundamentally different: estimation of $\theta$ relies on information from subsequent birth cohorts, while estimation of $\theta^{1}$ does not.
} 
initiatives were passed in years before or after their actual implementation dates. The latter analysis helps to ensure that the baseline estimates are not picking up the effects of unobserved shocks that preceded or post-dated the actual initiatives.

Note that in both models, the unit of observation is a state-cohort cell, not the individual.

As a result, estimates of $\theta$ and the vector $\left\{\theta^{k} ; k=-m, \ldots, l\right\}$ are representative of the long-run effects of the average state-funded kindergarten program, not the effect of state funding for the average student. While this parameter is also interesting, I am more interested in documenting the long-run consequences of the typical state's decision to fund kindergarten. Where microdata are used to estimate cohort-state averages, however, I use efficient weights, i.e., the number of observations used to calculate the dependent variable. Throughout, I limit attention to the 1954 to 1978 birth cohorts because they span the period over which most funding initiatives were passed, and doing so allows me to estimate the effects of kindergarten funding on long-run outcomes using ample pre-initiative data.

\section{State Funding, Kindergarten Programs, AND ENROLlMENT}

I begin the empirical analysis by examining how the funding initiatives affected the provision of kindergarten programs and kindergarten enrollment. I measure the supply of kindergarten programs with the fraction of school districts serving primary grades in a state that offered kindergarten, calculated using data on district-level grade spans from the Common Core of Data (CCD) and surveys preceding it. I approximate the kindergarten enrollment rate with the state kindergarten-to-first grade enrollment ratio, with enrollment aggregates drawn from the CCD and earlier published data. ${ }^{16}$ The first series spans 1962 to 1983 and the second spans 1959 to 1983 - the years in which the cohorts of interest would have been aged five - and samples are limited to treated states, as earlier discussed.

\footnotetext{
${ }^{16}$ See Appendix for more detail on these data.
} 
As already noted, schools in the treated region - and especially in the South - relied heavily on state funding for day-to-day operations, so the introduction of state funding for kindergarten would have provided a strong incentive to establish kindergarten programs. Figure II provides visual confirmation, plotting estimates of $\theta^{k}$ from a version of equation (1) where the kindergarten supply measure is the dependent variable (Panel A); 95 percent confidence intervals on these estimates are denoted with the dashed lines. ${ }^{17}$ In the first year in which funding was available, the supply of kindergarten programs in the typical treated state was 18.3 percentage points higher than it was in the year prior. Increases in kindergarten supply were more gradual thereafter, rising another 22 percentage points to plateau at a 40 percentage point gain in kindergarten supply by five years after an initiative was passed. Anecdotally, the gradual take-up of kindergarten over these years was due to a slow resolution of constraints on the supply side, such as shortages of classrooms and teachers, rather than a gradual ramp-up in local demand. ${ }^{18}$ While significantly higher in all years after state funding, the graph points to an economically and statistically significant pre-initiative trend in kindergarten supply. This prior trend is likely driven by the existence of pilot programs in some states, which funded a small number of kindergarten classes spread across multiple districts on a trial basis. ${ }^{19}$ Consistent with

\footnotetext{
${ }^{17}$ To account for the possibility that error terms are correlated within states across years (or cohorts below), I cluster standard errors on state (state of birth below) (Bertrand, Duflo, and Mullainathan, 2004). Because the number of clusters (24 in most cases) might be too small to produce tests of the correct size, I draw critical values from a tdistribution with degrees of freedom equal to the number of clusters, less two. Simulations presented in Cameron, Gelbach, and Miller (2008) suggest that this assumption yields only slight over-rejection of the null hypothesis in applications with 20 to 25 clusters.

18 Arkansas, for example, first appropriated funds for public school kindergartens in February of 1973, but within a month, passed another bill making funds available for kindergarten during the summer months "due to the lack of available classrooms, teachers, or for other reasons" (Acts of Arkansas 1973, Act 83, Section 1; Acts of Arkansas 1973, Act 143, Section 1). In addition, while foundation support began during the fall of 1967 in Maryland, it was clear by August of that year that kindergartens would not open everywhere because of "an insufficient supply of appropriate space and a professionally trained kindergarten teaching staff” (Harris, 1987, p. 118).

19 That is, due to pilot programs, districts offering kindergarten in the pre-initiative period may not have supported kindergarten classrooms for all children. Pilot programs were operated in Alabama, Georgia, Kentucky, North Carolina, South Carolina, Tennessee, and Texas. The programs in Texas and Georgia prioritized exceptional and low-income students; the program in North Carolina aimed to operate at least one kindergarten classroom in all districts.
} 
this interpretation, Panel B of Figure II shows a much weaker pre-initiative trend in the ratio of state kindergarten to first grade public enrollment. Here, the impact of funding is even more apparent: the public school kindergarten enrollment rate was 33.3 percentage points higher than it was the year before the initiative by the second year after its passage.

Figure II suggests that state funding had a strong effect on both the supply of seats in kindergarten programs and kindergarten enrollment. Table II summarizes these findings. As shown in column (1), simple differences-in-differences estimates of the effect of state funding on kindergarten supply and the public school kindergarten enrollment rate are quite similar, at 0.336 $(\mathrm{se}=0.092)$ and $0.340(\mathrm{se}=0.048)$, respectively. These effects are quite large, representing more

than a doubling of the variables' pre-initiative means, shown in the first row of each panel $(0.153$ and 0.146, respectively). Given the strong trends shown in Figure II, it is not surprising that linear fits of them are statistically significant, and that estimates of the average program effect from equation (3), shown in column (2), are much smaller in magnitude. Nevertheless, estimated coefficients on the post-initiative indicator remain statistically significant, and large: kindergarten supply was 16.5 percentage points higher than would have otherwise been expected in the post-initiative period and the kindergarten enrollment rate 23.1 percentage points higher. The next section investigates whether these developments were matched by a discrete change in the well-being of children who would have turned five after the initiatives were passed.

\section{STATE FUNDING AND LONG-TERM OUTCOMES}

\section{V.A. Data}

Data for the analysis of the initiatives' long-term effects were drawn from Public Use Microdata Samples (PUMS) of the Decennial Census. I consider a collection of outcomes that reflect the goals of state policymakers outlined above - an indicator for whether a child was 
below grade for age while still of school age (a proxy for grade retention) $;^{20}$ indicators for adult educational attainment (high school dropout, high school degree only, and some college); the natural log of wage and salary earnings and indicators for employment and receipt of public assistance income (all in the prior year); and an indicator for residence in institutionalized group quarters, a proxy for incarceration. ${ }^{21}$ I also consider self-reports of a disability that limits or prevents employment - a measure of physical health (e.g., Almond, 2006). Kindergarten funding might have indirectly affected physical health by reducing Head Start attendance, which has been found to have effects on this margin, at least during childhood (Currie and Thomas, 1995; Ludwig and Miller, 2007). It might also have done so directly by providing children access to school lunch and rudimentary health screenings.

For the analysis of grade retention, I draw my data from the 1970 (1 percent, Form 2 State) and 1980 (5 percent) Census PUMS and restrict attention to children ages six to fifteen as of the end of the third quarter in the prior year. The cohorts under consideration were thus born (roughly) between 1954 and 1973 and should have been of age to start kindergarten in fall 1959 through fall 1978. ${ }^{22}$ For the other outcomes, I base my analysis on data from the 5 percent Census PUMS from 1980, 1990, and 2000 and restrict attention to individuals born 1954 to 1978

\footnotetext{
${ }^{20}$ I use an indicator set to one if a child's grade was below the median among children born in the same quarter and year who reside in the same state (Oreopoulos, Page, and Stevens, 2006). Earlier versions of this paper (e.g., Cascio, 2004) used an additional measure - an indicator for whether an individual was enrolled in a grade below what he should have been given his age the prior October - and presented estimates from both the Census and October Current Population Survey (CPS). Results using this alternative measure in the Census are substantively similar to those presented and are available from the author on request. I am no longer presenting estimates using the October CPS due to concerns about selective migration subsequent to the initiatives; only state of residence is observed. In general, I prefer the measure presented over the alternative, since the measure presented is arguably subject to less misclassification (see Cascio, 2005).

${ }^{21}$ An individual is classified as institutionalized if they reside in a correctional institution, a mental health institution, or an institution for the poor. I cannot look just at residence in a correctional institution, since 1990 and 2000

Censuses do not distinguish between institutional types. The type of group quarters residence variable in the Census has previously been used as a measure of incarceration (e.g., Lochner and Moretti, 2004; Butcher and Piehl, 2005) or both incarceration and mental health (e.g., Borjas, Grogger, and Hanson, 2006).

${ }^{22}$ Under the assumption that entering kindergartners must be five years old in late September or early October, this definition of cohort captures a group of students who should have entered school together. A change in the education questions and lack of information on quarter of birth as the 1990 Census make it impossible to include later cohorts in this analysis.
} 
who were aged 21 to 35 as of the Census (April 1). For the purpose of this later analysis, I approximate cohort with Census year less age less one, since quarter of birth is not publicly reported in 1990 or $2000 .^{23}$ All samples are restricted to individuals with non-allocated data on birth state, race, age, and the relevant outcome before being collapsed to averages at the birth state-cohort-race-Census year level (see Appendix).

\section{V.B. Results}

Table III presents estimates of equation (3) for the outcomes described above. The table shows separate estimates by race, with samples restricted to individuals born in the treated states. In addition to the controls already discussed (i.e., state of birth fixed effects, cohort-by-education spending group of birth state fixed effects, and cohort-by-Southern region of birth fixed effects), the model includes fraction female in the cell and dummies for age and Census year. ${ }^{24}$ Regressions are now weighted by the number of observations used to calculate the dependent variable.

Since they were the first-order targets of policymakers, consider first estimates of the effects of kindergarten funding on grade retention and educational attainment, given in columns (1) through (4). As shown in Panel A, whites who were five years old after the typical state initiative had more education as adults. However, the effects are small in magnitude: the coefficient on the post-initiative dummy, $D_{s h}$, is -0.0038 in the model for high school dropout, representing only a 2.5 percent reduction on the pre-initiative cohort dropout rate of 15.4 percent (column (2)). The marginally significant estimated increase in college attendance for postinitiative cohorts is even smaller when expressed in these terms, at 1.3 percent $(-0.0065 / 0.502$;

\footnotetext{
${ }^{23}$ I then define the first treated cohort as that where all children would have in principle been eligible to attend kindergarten. If there were large changes in outcomes in the first year of funding availability, this will tend to bias my estimates downward.

${ }^{24}$ I have interacted age and year fixed effects with the funding category and Southern dummies and found very similar results (available on request).
} 
column (4)). ${ }^{25}$ The analogous estimates for blacks, in Panel B, suggest that affected cohorts attained lower levels of education. While not statistically significant, these estimates are large enough to rule out even the small positive gains in educational attainment for whites; $p$-values on tests of equality of the black and white coefficients are 0.043 and 0.0358 for the respective outcomes (final row).

Notably, the apparent gains in educational attainment for whites occurred without statistically significant reductions in grade repetition, either in absolute terms or relative to blacks. ${ }^{26}$ As shown in column (1), whites aged five after the initiative were less likely to be below grade for age and blacks more likely, but neither estimate is statistically different from zero, and the estimates are not statistically distinguishable from each other $(\not$-value $=0.715) .{ }^{27}$ Yet, the trend estimates point to at least a slight positive correlation between grade retention and high school dropout, making it potentially unsurprising that policymakers presumed the funding initiatives would have an impact on educational attainment if they facilitated grade progression. In particular, pre-initiative trends in both the grade retention proxy and high school dropout are negative for whites, and for blacks, post-initiative trend breaks for both outcomes are positive.

This correlation is shown more clearly in Figure III, which plots the event-study estimates from equation (1) for each of the education outcomes; $;^{28} 95$ percent confidence intervals are now represented by small dots, and the solid lines represent the coefficients presented in Table III, normalized to pass through these estimates. Perhaps most striking are the graphs for blacks (Panel B), which show clear jumps upward in the likelihood of being a high school dropout and

\footnotetext{
${ }^{25}$ Given the estimated "first stage" effect of kindergarten funding from this same specification (Table II, Panel B, column (2)), the implied effect of public school kindergarten attendance on white high school dropout is 1.6 percentage points (10.9 percent) and on white college attendance is 2.8 percentage points (5.6 percent). I prefer the interpretation given in the text because kindergarten funding may have affected outcomes through other channels.

${ }^{26}$ Misclassification in the grade retention proxy could, however, be attenuating the estimates (Cascio, 2005).

27 The estimates for educational and other outcomes are similar when I limit the sample to the same cohorts included in the estimation sample for below grade for age (available upon request).

28 The underlying specification also includes share female in the cell and age and year fixed effects.
} 
downward in the likelihood of having some college education for the cohort aged five in the year of the initiative. In the former case, the event-study coefficients are even statistically significant for the first two and several later affected cohorts. The corresponding figures for whites (Panel A) seem less striking despite the statistical significance of the underlying estimates, but this is in part because I apply the same scale across race for each outcome variable for the purposes of comparability; the coefficients for whites are much more precisely estimated. Nevertheless, the plot for white college attendance (last column) is not particularly compelling and suggests that the estimates, which are already relatively imprecise, may not be robust.

Before turning to the estimates for other outcomes, it is important to note that estimation of a standard differences-in-differences model would predict impacts of kindergarten funding that may not in fact be present. For example, there is a pre-existing downward trend in the likelihood of grade retention for whites, the linear estimate of which is statistically significant (column (1) of Table III, Panel A). Figure III makes clear that failure to account for this trend would generate a much larger coefficient on the post-initiative dummy than that which arises out of estimation of equation (3). Similarly, in a standard differences-in-differences model, the estimated effect of kindergarten funding on college attendance for whites would be negative not positive - and its seemingly perverse effects on grade retention, high school dropout, and college attendance for blacks much larger in magnitude.

Figure IV gives similar plots for employment and log wage and salary earnings. The graphs provide no evidence of an impact of state kindergarten funding on earnings for individuals of either race. Consistent with this observation, coefficients on the post-initiative dummy for log earnings (Table III, column (6)) are not statistically significant and not statistically distinguishable between blacks and whites $(p$-value $=0.461)$. Despite what may appear in the figure to be a significant decline in employment among blacks aged five after kindergarten 
funding, the coefficient on the post-initiative indicator is also insignificant for this outcome (column (5)) and not statistically different across race $(p$-value $=0.196) .{ }^{29}$ It might seem surprising that neither the additional education that whites received as a result of state funding nor the additional time spent in school for children of either race translated into higher earnings.

However, due to data constraints, I include in the sample individuals who are young and could still be enrolled in school, possibly leading to downward bias in the earnings estimates. ${ }^{30}$ The estimated effect of kindergarten funding on educational attainment is also small enough and the kindergarten program low-intensity enough that any earnings effect is too small to detect.

The final three columns of Table III present estimates for public assistance receipt and the proxies for incarceration and physical health described above. Here, the most notable finding is that whites of kindergarten age after passage of a funding initiative were less likely to reside in institutionalized group quarters as adults (column (8) Panel A); this is also demonstrated graphically in the upper panel of Figure V. The effect is large relative to that for white educational attainment, at 22 percent $(-0.0016 / 0.0073)$. The estimated effect of kindergarten funding on white disability rates (column (9)) is marginally statistically significant, but not as compelling when presented graphically. While I cannot reject that program effects for blacks and whites are identical, this only implies that the estimates admit small reductions in these outcomes for blacks, given the larger pre-initiative means on both variables for this subpopulation. Effects of the magnitude seen for whites are highly unlikely to have occurred for blacks. ${ }^{31}$

\footnotetext{
${ }^{29}$ Given lingering concerns about sample selection, I have also estimated models for real wage and salary earnings (in 2007 dollars), which include individuals with no income. These estimates (available on request) are qualitatively similar to those for log earnings.

${ }^{30}$ In principle, it should be possible to observe the cohorts of interest at older ages using more recent data from the American Community Survey, which administers the Census long form to smaller samples on a monthly basis. However, information on survey month is needed to determine cohort and is not available in the public use files. ${ }^{31}$ Lower bounds on the 95 (90) percent confidence intervals for blacks are -0.0043 (-0.0034) for institutionalization and -0.0069 (-0.0055) for disability, which represent 14.5 (11.6) percent and 8.5 (6.7) percent of the pre-initiative means on these respective variables.
} 


\section{V.C. Robustness}

The baseline specification was chosen to mitigate bias, controlling in a relatively unrestricted way for inter-cohort trends in outcomes and permitting trends in outcomes relative to the introduction of state funding for kindergarten. Table IV probes the robustness of these estimates further. The table gives estimates of the coefficient on the post-initiative indicator from different specifications and when equation (3) is estimated on different subsamples. For comparison, the first row of each panel gives the estimates of this coefficient from Table III.

Identification relies on the assumption that unobservables are uncorrelated with the introduction of state funding for kindergarten. If this assumption holds, we might expect the estimates to change very little with the addition of observed correlates of outcomes to specification (3). The second and third rows of each panel of the table explore this possibility. Row 2 adds to the baseline model a vector of cohort-specific family background characteristics, estimated from the 1960, 1970, and 1980 Censuses. ${ }^{32}$ These additional controls change the estimates very little, which is not surprising given that significant relationships between them and the post-initiative indicator arise about as often as would be expected through pure chance (Appendix Table I)..$^{33}$ Adding a measure of labor market conditions - the unemployment rate in a cohort's state of birth at age 20 (row 3) - similarly has little impact on the estimates. ${ }^{34}$

\footnotetext{
32 Some of these characteristics (maternal average highest grade completed, age, and number of children ever born and the share of mothers heading the household) were calculated by matching children to their likely mothers based on household and subfamily relationship variables. The others (the fraction of homes with no phone, no air conditioning, no car, and no plumbing, and rooms per person) are simply characteristics of the household in which the average child in a cohort resided. Samples include the relevant cohorts observed at the youngest possible age across the three Census years and drop observations with allocated data on age, place of birth, and race. See the Appendix for more details. Family background data are not available for blacks in all cohorts for which outcomes data are available; see Appendix Table I.

${ }^{33}$ The estimates presented in Appendix Table I are based on the sample underlying the estimates in columns (8) and (9) of Table III. Estimates based on other samples are similar and available from the author on request.

${ }^{34}$ These additional controls tend to significantly improve model fits, and individual coefficients tend to have the expected sign.
} 
Another approach to testing the model's identifying assumption is to examine how the estimates change under even less restrictive specifications of the cohort effects. The next rows of Table IV consider two such specifications: row 4 adds linear birth state-specific cohort trends, and row 5 interacts the two sets of cohort effects in the baseline model. The former specification leads to very little change in the estimates. The latter specification has more of an impact, yielding estimates for college attendance and disability for whites that are smaller in magnitude and no longer statistically significant. This suggests that the baseline estimates for these outcomes were in part picking up differential cohort trends across more narrowly-defined subareas of the treated region. Consistent with this, restricting attention to the Southern born (row 6) also yields smaller estimates for these outcomes. The estimated effect of kindergarten funding on high school dropout for whites is also no longer statistically significant in this subsample, suggesting that using variation from all treated states is helpful in improving precision.

As a final check on identification, I re-estimated equation (3) replacing the policy variables with their counterparts under the assumption that kindergarten funding was introduced in one-year increments up to five years before and five years after its actual implementation date, in essence estimating the effects of a series of "placebo" initiatives. If my baseline estimates are picking up the effects of kindergarten funding - not some earlier or later unobserved shock or intervention - the largest estimates of program effects should arise from estimation of the model as originally specified. For whites, this is the case for two of the four outcomes for which I detected some effect of kindergarten funding - high school dropout and institutionalization (Appendix Figure II, Panel A). The pattern of estimates for institutionalization in particular is also remarkably similar to those for kindergarten supply and enrollment (Appendix Figure III), further suggesting the plausibility of the baseline estimates for this outcome. ${ }^{35}$

\footnotetext{
${ }^{35}$ Similar plots for other outcomes are available on request from the author.
} 
Finally, I estimate the equation (3) separately by sex (rows 7 and 8 of Table IV). The findings reveal that the effect of kindergarten funding on institutionalization for whites is driven by its effect on men, for whom the institutionalization rate is much higher. The magnitude of the effect for white men is similar to that observed for whites overall (a reduction of 23 percent, or $-.0029 / 0.0122)$, and as was the case with the pooled estimates, it is possible to rule out an effect of the same magnitude for black men. The estimates also reveal that the significant differences in effects of kindergarten funding on educational attainment across race are driven by women; kindergarten funding is also associated with significantly lower earnings for black women, and the difference in the post-initiative coefficients for log earnings across race for women is statistically significant. To the extent that kindergarten funding displaced black enrollment in more intensive early education - a possibility that I explore in the next section - these findings would be consistent with recent findings that girls are more responsive to intensive preschool interventions (e.g., Anderson, 2008). ${ }^{36}$

\section{WHY DID BLACKS NOT BENEFIT?}

The estimates in Tables III and IV imply that most positive impacts on children of state subsidization of kindergarten were small, which is reassuring given the low-intensity nature of the program. What is potentially unexpected, however, is that the funding initiatives only appear to have had positive effects for whites. White children turning five years old after kindergartens secured state funding were less likely to be either high school dropouts or institutionalized as adults. For blacks, by contrast, I find no statistically significant positive impacts of the program and can generally rule out positive effects of the magnitude observed for whites.

What might explain these findings? Earlier discussion alluded to three broad hypotheses for why blacks might not have benefited as much as whites from the funding initiatives: (1)

\footnotetext{
${ }^{36}$ Ludwig and Miller (2007) report finding slightly larger effects of Head Start on educational attainment for women,
} while Garces, Currie, and Thomas (2002) report significantly larger effects for men. 
Kindergarten funding may have disproportionately drawn blacks out of higher-quality education settings; (2) Instead of raising additional revenue to fund local kindergarten programs, school districts offered lower-quality kindergarten programs to blacks or moved funds from existing school programs from which blacks may have disproportionately benefited; and (3) Blacks were more adversely affected by any subsequent "upgrading" of school curricula. This section explores the empirical relevance of each of these hypotheses in turn. The first receives the most support, but since the available data are not ideal, this conclusion should be viewed as tentative. ${ }^{37}$

\section{VI.A. Hypothesis 1: Crowd out of Other Early Education}

Crowd out of Private Kindergarten Attendance and Enrollment in Other Grades. Two alternatives to public school kindergarten attendance that immediately come to mind are enrollment in private kindergarten and in later grades. If private kindergartens were of comparable quality to public kindergartens, children moving from private to public kindergartens after the state funding initiatives would have experienced no change in well-being, and the estimated reduced-form improvement in outcomes would be smaller the greater the extent of crowd-out. By contrast, enrollment of five year olds in first grade (or above) might have been what is considered today “developmentally inappropriate," in which case crowd-out would have unambiguously improved a child's outcomes. Given financial considerations, the average black child was arguably less likely to switch from private kindergarten and more likely to switch from later grades, suggesting that crowd-out of this nature cannot explain the findings.

To confirm this, Table V presents, separately by race, estimated effects of the funding initiatives on the enrollment of five year olds in public kindergarten, school overall, private kindergarten, and grades besides kindergarten, based on data from the October Current Population Survey (CPS). Because state of residence is not identified until 1977, the unit of

\footnotetext{
${ }^{37}$ Because the underlying publications and surveys are numerous, I leave detailed descriptions of the data sources used in this section to the Appendix.
} 
analysis is a grouping of states that is consistently observed over the sample period (1968-1983, or individuals born roughly 1963-1978), and the treatment variable is the population-weighted fraction of states in that group (hereafter referred to as a "CPS region") having passed a funding initiative. ${ }^{38}$ As a result, the estimates are more comparable to those presented in column (1) rather than column (2) of Table II and are subject to the same caveats. ${ }^{39}$ In addition to including fixed effects for CPS region, I control for cohort effects in as close a way as possible to the earlier analysis, interacting year (cohort) dummies with both a dummy for Southern Census division of residence and dummies for three groupings of the CPS regions based on expenditure per pupil in the mid-1960s (see Appendix).

The estimates presented in Table $\mathrm{V}$ are generally consistent with the intuition given above. The private kindergarten enrollment rate of whites over the entire sample period was nearly triple that of blacks (14.1 percent versus 5.7 percent), and 36 percent of new white public kindergartners would have otherwise been enrolled in a private kindergarten. Funding of kindergarten by all states in a region was associated with a 27.3 percentage point increase in the white public kindergarten enrollment rate (Panel A, column (1)) and a 9.7 percentage point reduction in the white private kindergarten enrollment rate (column (5)). The reduction in private kindergarten attendance of blacks (Panel B) is significantly lower than that observed for whites $(p$-value $=0.0313)$, at 4.7 percentage points. However, neither blacks nor whites experienced a significant reduction in enrollment in other grades (column (6)).

These findings imply that black five year olds were more likely than white five year olds to have been drawn into school by the funding initiatives. The fraction of black five year olds not enrolled in school was 17.5 percentage points lower once all states in a region funded

\footnotetext{
${ }^{38}$ Estimates for kindergarten supply, enrollment, and adult outcomes are similar when I limit the estimation samples to 1963 and later cohorts (available upon request).

${ }^{39}$ Conclusions based on Census data on five year olds observed from 1960, 1970, and 1980 are substantively similar (available on request).
} 
kindergarten (column (4)), accounting for 80 percent of the 21.9 percentage point rise in the black public kindergarten enrollment rate. For whites, this figure was 49 percent $(0.135 / 0.273)$. Assuming that time spent in a public kindergarten was more productive than time spent at home and at least as productive as time spent in a private kindergarten, these findings suggest that, if anything, there should have been positive effects of kindergarten funding that were larger in magnitude for blacks than whites.

Crowd-out of Enrollment in Other Publicly-Funded Early Education Programs. The October CPS cannot reveal all crowd-out since it does not separately categorize enrollment in kindergartens with different sources of public funding (e.g., federal Title I funding versus state and local funding) or enrollment in different types of publicly-funded early education programs that respondents might categorize as kindergarten (e.g., Head Start). Given much higher enrollment rates among blacks and existing estimates of the program's long-term effects, substitution from Head Start in particular might have had deleterious impacts for blacks that would offset any positive impacts in a reduced-form model.

Is there any evidence to support the hypothesis of "public-public" substitution? The first column of Table $\mathrm{V}$ hints to the possibility, in that blacks had a public kindergarten take-up rate that was 5.4 percentage points lower than that for whites $(p$-value $=0.133)$, despite having roughly the same enrollment rate as whites over the sample period (0.595 versus 0.59$)$. As earlier noted, administrative sources on Head Start also show declines in the enrollment of children aged five from the late 1970s forward, when they first report the age breakdown of enrollment. Unfortunately, these sources do not provide state (or even region) level data.

For this, I first turn to the Panel Study of Income Dynamics (PSID), which in 1995 asked respondents under the age of 40 questions about their Head Start enrollment experiences. In particular, information is available on whether an individual ever attended Head Start, and if so, 
age when first attended and length of enrollment. I use these data to construct an indicator for whether a respondent was likely to have attended Head Start at age five (see Appendix). ${ }^{40}$ Both because this data set is small and for comparability to estimates already presented from the October CPS, I limit the sample to respondents who would have been five years old between October 1963 and October 1978 and conduct the analysis at the CPS region - cohort level.

The resulting estimates, presented in the final column of Table V, suggest that the introduction of state funding for kindergarten did indeed prompt a reduction in Head Start participation among blacks. The existence of kindergarten funding among all states in a CPS region, relative to none, was associated with a statistically significant 24.9 percentage point reduction in the likelihood that a black child attended Head Start at age five. Given an enrollment rate of 25.7 percentage points across the observed cohorts, this estimate implies that state funding for kindergartens essentially eliminated enrollment of black five year olds in Head Start. By comparison, enrollment of whites in Head Start at age five was much lower (2 percent) and the change in enrollment after the average funding initiative close to zero (Panel A). A test of the null of no difference in the post-initiative coefficients for blacks and whites yields a $p$-value under 0.01 .

Complementary evidence comes from annual, county-level data on federal outlays for Head Start, which I aggregate to the state-year level. The same source also provides information on federal outlays for Title I, and therefore provides some insight into cross-program substitution on this margin as well. ${ }^{41}$ Table VI, Panel A presents estimates of the post-initiative coefficient from equation (3) for two different specifications of Head Start funding (in 2007 dollars) - the natural log of funding and funding per four year old - and analogous estimates for Title I

\footnotetext{
40 These data were used in Garces, Thomas, and Currie (2002). The 1979 National Longitudinal Survey of Youth also asked respondents retrospective questions about Head Start enrollment in the mid-1990s, but covers only cohorts born 1960 through 1964 and does not ask about ages at which enrolled.

41 These data were used by Ludwig and Miller (2007). See Appendix for sources and details on the sample.
} 
(normalized instead by enrollment in grades one through 12); Figure VI gives the fits from these models along with the corresponding event-study estimates. The estimates for Head Start funding are noisy, but broadly consistent with those found in the PSID: the average kindergarten funding initiative was associated with, for example, a 6 percent reduction in Head Start outlays to a state, but the estimate is not statistically significant (standard error $=0.053$ ). There is no graphical or statistical evidence of an impact of kindergarten funding on Title I outlays. ${ }^{42}$

Together with historical accounts of the importance of Head Start in providing education for five year olds in the absence of state-funded kindergartens earlier discussed, these independent estimates strengthen support for the hypothesis that state funding for kindergartens crowded out enrollment of black five year olds in federally-funded early education for the poor. The literature lacks estimates of the effect of Head Start at age five, making it difficult to gauge the extent to which this substitution would have offset positive impacts of kindergarten attendance elsewhere in the black population. However, a back-of-the-envelope calculation based on the estimates presented above and those given in Ludwig and Miller (2007) - who use variation from essentially the same time period and population considered here - suggests that the reduction in Head Start attendance among blacks may account for at least 16 percent of the 1.13 percentage point increase in the black-white gap in high school dropout rates after the initiatives were passed. ${ }^{43}$

\footnotetext{
42 This is perhaps not that surprising, given that unlike Head Start, Title I was not a matching grant program. Instead, counties were allocated grants based on child poverty counts, and local education agencies within those counties could apply for funds through the state. Funds that might have otherwise been allocated to kindergarten under Title I were likely simply moved to other programs.

${ }^{43}$ Ludwig and Miller (2007) estimate that grant-writing assistance to the poorest counties in the country led to a gain in Head Start funding per four year old of around \$130 in both the 1968 and 1972 fiscal years (nominal dollars) and at least a 3 percentage point increase in the likelihood of high school graduation. This implies an increase in high school graduation of 0.45 percentage points for every additional $\$ 100$ (2007 dollars) of Head Start outlays per four year old, or a 0.1845 percentage point increase in high school dropout with a $\$ 41$ reduction in Head Start outlays per four year old (Panel A, Table VI). Calculations based on Ludwig and Miller's estimates for Head Start participation suggest that a greater proportion of the rise in the black-white high school dropout gap can be explained.
} 


\section{V.B. Hypothesis 2: School Resources}

The funding initiatives might have led to crowd out along another dimension. State funding, while generous, would not have been sufficient to cover the costs of operating a kindergarten program. If the average school district did not raise the necessary extra funds from local (or federal) sources, the quality of kindergarten programs - or other school programs - may have suffered. This resource shifting would have had larger negative effects on blacks if districts or schools serving more blacks were less likely to raise this revenue, or if, conditional on not raising it, there were greater reductions in quality of kindergartens attended by blacks or in other school programs, like class size reduction, from which blacks may disproportionately benefit (e.g., Card and Krueger, 1992; Krueger and Whitmore, 2002). Evidence on this type of reaction to the funding initiatives is mixed.

Did school districts supplement the state grants for kindergarten with local and state funds, and did the degree of supplementation differ by racial composition? Unfortunately, data do not exist to answer the latter question, but it is possible to gain some insight into the former using published state-year data on revenues overall and by source. Panel B of Table VI presents estimates of equation (3) using these data, which I have normalized by enrollment in grades one through twelve. While not statistically significant, the magnitude of the post-initiative coefficient for state revenue is in the neighborhood of what would be expected given funds allocated per student by the typical initiative. ${ }^{44}$ Given the pre-existing fraction of revenue raised from state sources in the typical treated state (around 50 percent), we would expect districts roughly to match this figure through a combination of local taxation and federal grants if they operated kindergarten programs of the same quality as education in later grades. The post-initiative

\footnotetext{
44 The average treated state in the South, for example, contributed \$1708 per half-day kindergarten student (2007 dollars), yielding an expected rise in state revenues of $\$ 142$ per student enrolled in first through twelfth grade. I have not extracted this information from the legislation of treated states outside the South, but would expect the average state contribution to be lower given lower state contributions to school revenue in general in these states.
} 
coefficient for local revenue is in fact negative, and while positive, that for federal revenue is smaller in magnitude, making the overall increase in per-pupil revenue less than the additional contribution from the state. ${ }^{45}$ However, lack of precision on the estimates makes it impossible to rule out that school districts fully matched the state grant through other sources.

An arguably more direct approach to the same general question is to estimate effects of the state funding initiatives on resources devoted to black and white students. I am able to do so for two outcomes - the length of kindergarten day (in the October CPS) and class size, as proxied by the pupil-teacher ratio (available through 1972) - and the estimates do not support the conclusion that blacks were shortchanged relative to whites. Black five year olds were if anything more likely than whites to enter full-day kindergarten programs (columns (2) and (3) of Table V), and the difference in pupil-teacher ratios experienced by black and white students actually fell, albeit insignificantly, after the average funding initiative was passed (Table VI, Panel C).

\section{V.C. Hypothesis 3: Curricular Change}

Anecdotally, the kindergarten curriculum has become more academically oriented and expectations of first graders have increased over time. The establishment of kindergartens in a public school system might have prompted this shift - as children arrived in first grade better prepared - or it may have been a broader trend. Upgrading of the curriculum would have presented more challenges for those at the bottom of the achievement distribution.

Given the limited data available on school resources, it is not surprising that data on curriculum - separately by race but even in general - is essentially non-existent, rendering a direct test of this hypothesis impossible. Instead, I test whether the funding of kindergartens led states to raise the age requirements for school entry or to fund pre-kindergartens more quickly - both potential indicators that existing students were failing to meet the prevailing academic standard at

\footnotetext{
${ }^{45}$ Estimates in natural logs are qualitatively similar (available on request).
} 
the start of school. To estimate these models, I return to a cohort-level analysis, focusing once again on individuals born 1954 to 1978. I measure the first variable with the deviation (in days) of a state's first grade entry cutoff birthdate from September 1 when the cohort was aged six ${ }^{46}$ and the second with an indicator for whether pre-kindergarten had been funded in a state by the time the cohort reached four years old. Panel D of Table VI shows that kindergarten funding was not associated with changes in either of these policies. However, these estimates must be viewed with caution, since state governments may had have other motivations for changing school entry laws and funding pre-kindergarten, and neither is a direct measure of curriculum.

\section{CONCLUSION}

While there is great interest among policymakers in extending free early education to disadvantaged children, evidence to date on long-run effects of preschool has been limited to experimental evaluations of model preschools and non-experimental studies of Head Start. This paper has attempted to fill out this literature by estimating the long-term effects of an historical episode of public investment in universal early education - the introduction of state funding for public school kindergartens in the 1960s and 1970s. I find evidence of lower high school dropout and institutionalization rates for whites - but not blacks - who turned five after the typical state reform, and detect no impacts of state funding for children of either race on other margins that were targeted by reformers. The most likely explanations for these findings are the low-intensity nature of kindergarten as an early intervention and the likely substitution of public kindergarten for Head Start attendance for a critical mass of black five year olds.

These findings complement those of existing research on the long-term effects of targeted programs. First, they suggest that, in the absence of higher quality alternatives, participation in a low-intensity preschool program may have some positive long-term effects.

\footnotetext{
${ }^{46}$ Estimates are qualitatively similar when I use a dummy set to one after the first observed switch to an earlier
} school entry law. 
Second, the existence of alternatives - particularly higher-quality alternatives for disadvantaged children - may diminish the effectiveness of universal programs. Though there are obvious caveats on generalization, higher rates of preschool participation among children today suggest that, if anything, any positive reduced-form long-term effects of extending universal public schooling to four year olds are likely to be smaller than those estimated here. ${ }^{47}$ Whether this finding will be borne out will only be discovered in the years to come.

${ }^{47}$ This is reflected in estimates of the effects of universal kindergarten during the period and universal prekindergarten today on maternal labor supply (cf. Cascio (2009) and Fitzpatrick (2008)). 


\section{APPENDIX}

\section{STATE FUNDING INITIATIVES}

The year of first state funding for kindergarten (Table I) is that at which all school districts within a state were either first entitled to state funding for the establishment and maintenance of public school kindergartens within their boundaries or could first apply for funds for that purpose. Since a single document bringing together the necessary dates was not available, they were culled from a variety of sources on a state-by-state basis. Seven types of documents were used:

1. State session laws, including appropriations acts;

2. Dissertations (Murray, 1973; Chapman, 1975; Forgione, 1977; Lightfoot, 1982; Harris, 1987);

3. A periodic publication of the U.S. Department of Health, Education and Welfare Office of Education giving details on state funding of education, including funding formulas (1963a, 1963b, 1967, 1969, 1972, 1976, 1980).

4. Compilations of legislation by the Education Commission of the States (1971a, 1971b, 1972, 1973, 1974a, 1974b, 1974c, 1974d, 1975a, 1975b, 1976);

5. Compilations of legislation by the National Education Association (1966, 1967, 1968, 1969, 1971, 1972, 1973);

6. State reports (Alabama Department of Education, 1977; Jones, 1977; Texas State Department of Community Affairs, 1972; Watson and Lanham, 1971);

7. Newspaper and journal articles (Tanner and Tanner, 1973; Kanensiger, 1983).

\section{DATA ON SCHOOL RESOURCES AND ENROLLMENT}

\section{II.A. Kindergarten Supply}

Kindergarten supply (Figures I and IIA, Table II, and Appendix Figure III) is measured as the fraction of school districts offering first grade in a state that also offer kindergarten. Data were drawn from published state tabulations and computer-coded microdata of grade span at the district level. Education Directory: Public School Systems (fall 1967) and Elementary and Secondary Education Directory: Public School Systems (fall 1968 to fall 1970) give state-level tabulations based on all operating public school districts. District-level microdata for all operating public school districts are available at ICPSR for various academic years from fall 1972 forward: Elementary and Secondary General Information System (ELSEGIS): Public School District Universe Data (fall 1972 to fall 1979, not including fall 1974), ${ }^{48}$ Common Core of Data (CCD): Public School Districts (fall 1980 to fall 1983) Common Core of Data: Elementary/ Secondary Education Agencies (fall 1985), ${ }^{49}$ and Common Core of Data: Public Education Agency Universe (fall 1986 through fall 1990). ${ }^{50}$

To create the longest possible consistent series, the published tabulations of grade span for fall 1967 through fall 1970 were replicated using the microdata for later years. Published

\footnotetext{
48 ICPSR \#2125 through \#2131, inclusive.

${ }^{49}$ ICPSR \#2132 through \#2136, inclusive.

50 ICPSR \#2423, \#2424, \#6904, \#2427, and \#2430, respectively.
} 
tabulations included the following categories: K-6, 1-6, K-8, 1-8, K-9, 1-9, K-12, 1-12, 7-12, 9-12, and other. School districts were similarly categorized at the state level from fall 1972 through fall 1990. The number of school districts offering kindergarten in a given state and year was then coded as the sum of districts in each of the following categories: K-6, K-8, K-9, and K-12. The rate of kindergarten availability is then this sum, divided by the sum of districts in the K-6, K-8, K-9, K-12, 1-6, 1-8, 1-9, and 1-12 categories.

To extend the series back in time, I created comparable tabulations based on published data from Education Directory: Public School Systems from fall 1963, fall 1964, and fall 1966. The 1963 and 1964 publications include summary tables comparable to those included in the fall 1967 to fall 1970 publications $^{51}$; no such tabulations were included in the 1966 publication, so I calculated kindergarten provision rates based on hand-counts of district-level grade spans in published volumes (treated states only). The key limitation of these three years of data is that they pertain only to school districts with at least 300 children enrolled.

Because district-level enrollment data in the underlying publications are given in the prior year's version of the publication from which I draw enrollment aggregates (see Section II.B of this Appendix), I lag the resulting series on kindergarten supply by one year. It thus spans the academic years 1962-63 through 1989-90, with missing data for 1964-65, 1970-71, 1973-74, and 1983-84.

\section{II.B. Kindergarten and First Grade Enrollment}

The ratio of public school kindergarten to first grade enrollment (Figures I and IIB, Table II, and Appendix Figure III) was calculated using state-level grade-specific enrollment figures from two annual administrative sources. ${ }^{52}$ Data from 1964 to 1982 was hand-entered by the author from annual publications of the Office of Education. Although they appear to be part of the same series, the publications go by different names over the period. ${ }^{53}$ Data were garnered through federal survey of each state, the form of which was largely consistent from year to year. Most states are reported to have gathered relevant information on enrollment from school districts by way of a similar survey. Enrollment figures were taken as of October of the year. Data from 1983 to 1985 were drawn from the Common Core of Data: State Nonfiscal Survey, a publication of the U.S. Department of Education (ICPSR \#6947). Data from 1986 to 2004 (not including 1995 and 1997) were downloaded from the National Center for Education Statistics. ${ }^{54}$ The universe of the State Nonfiscal Survey includes all elementary and secondary education agencies in the fifty states. This series is likely to be a continuation of the one earlier described.

Until 1979, the "pre-primary" enrollment category in the published data was inclusive of attendance at both kindergartens and preschools operated as part of a state's public schools. As of 1979, public preschool provision was rare in the treated region. Only nine treated states

\footnotetext{
51 The summary table for 1963 includes categories that are grouped as "other" in 1964 and later years.

${ }^{52}$ Data on total enrollment in grades 1 to 12, used to calculate per-pupil revenue (Table VI), were taken from the same sources.

${ }^{53}$ Including Statistics of State School Systems (fall 1958 to fall 1963, not including fall 1960), Statistics of Public Elementary and Secondary Day Schools (fall 1964 to fall 1967), Fall Statistics of Public Schools (fall 1968 to fall 1976), Statistics of Public Elementary and Secondary Schools (fall 1977 to fall 1980), and Public School Enrollment, United States (fall 1981 to fall 1982). $54<<$ http://nces.ed.gov/ccd/stfis.asp >>, accessed March 18, 2007. Data used include version 1c (fall 1986 to fall 1989, fall 1991, and fall 1996), version 1d (fall 2004), and version $1 \mathrm{~b}$ (all remaining years).
} 
(Alaska, Florida, Maryland, Montana, North Dakota, Oklahoma, Oregon, Texas, and Virginia) reported non-zero pre-kindergarten enrollment, and proportions of total pre-primary enrollees in pre-kindergarten in these states was low $(0.051,0.036,0.104,0.016,0.093,0.019,0.083,0.079$, and 0.018 , respectively). Using pre-primary enrollment aggregates through 1979 and kindergarten enrollment aggregates thereafter likely presents little loss in consistency of the enrollment series over time.

\section{II.C. Federal Outlays for Head Start and Title I}

State-year federal outlays for Head Start and Title I ESEA (Table VI and Figure VI) were calculated using county-level federal outlays data acquired from the National Archives and Records Administration (NARA) (for fiscal years to through 1975 and fiscal years 1983 and 1984) ${ }^{55}$ and ICPSR Study \#6029 (for fiscal years 1976 to 1980). The resulting series span fiscal years 1968 to 1984 for Head Start outlays (not including 1969, 1981, and 1982) and fiscal years 1969 to 1984 (not including 1980 to 1982) for Title I. ${ }^{56}$ Outlays were converted into 2007 dollars using the CPI-U (1982-84=100).

Ludwig and Miller (2007) note that the earliest years of the NARA data "have some obvious errors and are poorly documented" 57 and in their analysis used only data for years that "data from the electronic files matched published figures for total federal spending and Head Start spending at the national level, and the data matched for Head Start at the state level as well" (p. 200). I also compared sums calculated from the county-level files to published data at the federal level and by treated state (where available) to assess the viability of the data for my statelevel analysis. When I compared the state-level Head Start outlays I calculated to those reported in Jones (1979) for fiscal years 1970 through 1977, the correlation coefficient was above 0.975 in all fiscal years except 1974, where Mississippi was an obvious outlier. I therefore dropped fiscal year 1974 data for Mississippi from the Head Start analysis. I also dropped fiscal year 1983, since the total federal outlay calculated from the county-level data well exceeded the published appropriation, and without published state level data, it was impossible to confirm which if any states were the cause of the deviation. Unfortunately, I lack the data with which to do a similar exercise for Title I funding, so use all available data.

\section{II.D. School Resources}

School resource measures underlying the regression models shown in Table VI were hand-entered from a number of sources.

Data on revenues overall and by source (local, state, federal) are from various years of the Digest of Educational Statistics (1963-64 to 1983-84) and Statistics of State School Systems (1959-60 and 1961-62). Revenue data are not available for academic years 1960-61, 1962-63, 1964-65, 1972-73, and 1981-82, and only estimates are reported for available even years 1974-75 and prior. Expenditures per pupil in average daily attendance for the 1964-65 academic year (Appendix

\footnotetext{
${ }^{55}$ Federal Outlays System Files, FY 1968- 1975 (32 Files) (XMIS\# 006943 - 006950, 006957-006964, 006969-006976, 006985-006992) and CFFR Files, FY 1983-1984 (6 files) (XMIS\# 078182, 078200, 078218, 078183, 078201, 078219)

56 A fiscal year of $t$ corresponds to an academic year commencing $t-1$.

${ }^{57}$ For example, the last digit of the outlay is often a character. For this reason, I rounded all county-level outlays drawn from these data to the nearest thousand.
} 
Figure I) were hand-entered from the same publications that provided enrollment by grade and state for the same year (see Section II.B of this Appendix). Revenue and expenditure figures were converted into 2007 dollars using the CPI-U (1982-84=100).

Data on race-specific pupil-teacher ratios were taken from two sources: state-level data from Card and Krueger (1992) (for fall 1960, 1962, 1964, and 1966) and school-level data from Office for Civil Rights Surveys (for falls 1967, 1968, 1970, and 1972). In the former case, ratios were already reported separately by race. In the latter case, I arrived at race-specific pupil-teacher ratios by first calculating pupil-teacher ratios at the school level, then creating a weighted average of these ratios, with weights equal to the share of the state's total reported black or white enrollment attending that school.

\section{CEnSUS MiCRodATA}

Census microdata were used for three parts of the analysis: (1) analysis of grade retention (1970 and 1980); (2) analysis of adult outcomes (1980, 1990, and 2000); and (3) calculation of average cohort family background $(1960,1970$, and 1980). Samples include white and black persons in one of the 24 states with kindergarten funding initiatives after 1960 (Table I). Person weights (relevant for 1990 and 2000 Censuses only) were used in calculating cohort-state of birthrace-(and if applicable, Census year) specific averages of key variables.

For (1), the analysis includes individuals who were between 6 and 15 years of age as of October 1 prior to the Census, or individuals in the cohorts 1954 and 1973, where cohort is defined as census year - age at observation (April 1 of census year) - 1 (for second and third quarter births) and census year - age at observation (for first and fourth quarter births). I define cohort in this way so as to get as close as possible to an "academic" cohort, or a group of students who should have started kindergarten in the same year, given their birthdates. ${ }^{58}$ This definition also allows the Census analysis to be comparable with the analysis based on the October CPS. For (2), the analysis includes individuals ages 21 to 35 as of the Census (April 1) in the 1954 through 1978 birth cohorts, where cohort is defined as census year - age - 1; quarter of birth is not reported in 1990 and 2000, making it impossible to calculate each respondent's calendar year of birth in these years. For both (1) and (2), cohort is defined analogously when calculating average values for family background variables.

\section{IV.A. Grade retention}

Data for the grade retention estimates (Tables III and IV and Figure III) were drawn from the 1 percent 1970 Form 2 State PUMS and 5 percent 1980 PUMS. ${ }^{59}$ In addition to the sample restrictions noted above, I dropped observations with allocated values for age, place of birth, race, or school enrollment. An individual is classified as "below grade" if not currently enrolled or currently enrolled in a grade below the median for individuals born in the same quarter and year and currently residing in the same state.

\footnotetext{
58 The cutoff date for first grade entry tends to fall in either September or October for the cohorts and states under observation (author's calculations from relevant state session laws).

${ }^{59}$ ICPSR \# 18 (1970), ICPSR \#8101 (1980).
} 


\section{IV.B. Long-run outcomes}

Data for adult outcomes (Tables III and IV and Figures III, IV, and V, and Appendix Figure II) were drawn from the 5 percent PUMS of the 1980, 1990, and 2000 Censuses. ${ }^{60}$ In addition to the sample restrictions noted above, I dropped observations with allocated age, place of birth, or race. Before collapsing the data to Census year-cohort-state of birth-race averages, I further dropped allocated values of each outcome variable, one by one. ${ }^{61}$ Dropping allocated outcomes data may reduce bias if state of birth and year of birth were not used for imputation (Hirsch and Schumacher, 2004). For the analysis of wage and salary earnings, I also dropped observations where its real value (2007 dollars) exceeded $\$ 214,193$, the maximum it undertakes across the three Census years. Earnings were converted to 2007 dollars using the CPI-U (1982$84=100)$.

I define outcome variables as consistently as possible given that underlying variables tend to differ in 1980 relative to 1990 and 2000. First, questions on educational attainment in 1980 allow for calculation of number of years of completed schooling ("years"), whereas in 1990 and 2000, degree obtained is identified. I define education outcomes on the basis of degree attainment, approximating high school dropout, high school completion, and some college with years $<12$, years $=12$, and years $>12$, respectively, in 1980. Second, the group quarters type question separately identifies three types of institutions (correctional, mental, and for the elderly, handicapped, and poor) in 1980, but not in 1990 or 2000. For the purpose of the analysis, I therefore define institutionalization as including all three types of institutions.

Other outcomes were constructed as follows. A respondent is coded as having a disability if $\mathrm{s} /$ he claims to have a disability that either limits or prevents employment. A respondent is coded as having received public assistance if $\mathrm{s} /$ he reports positive public income.

\section{IV.C. Family background estimates}

Average maternal characteristics by cohort, state of birth, and race were calculated by matching children to their likely mothers based on household and subfamily relationship variables in the 19601 percent PUMS, the 19701 percent PUMS (Form 2 State), and the 19805 percent PUMS. ${ }^{62}$ Samples were limited to the youngest children for which the relevant and complete cohorts can be observed. In 1970 and 1980, I dropped observations where any of the following were allocated for the child - place of birth, race, and relationship to the household head - and where any of the following are allocated for the mother - relationship to the household head and sex; allocation flags for these variables are not provided in the 1960 Census. In all years, I dropped observations where child age was allocated.

Average housing characteristics by cohort, state of birth, and race were also calculated using data on the same samples from the 1960,1970, and 1980 Censuses (same PUMS as above).

\footnotetext{
${ }^{60}$ ICPSR \# 8101 (1980), ICPSR \#9952 (1990), and ICPSR \#13568 (2000).

${ }^{61}$ For example, I drop observations with allocated income for the analysis of income, but retain observations with allocated values of other outcome variables. There are four relevant sets of allocation flags, which apply to income, education, employment in the previous year, and receipt of public income. There are no allocation flags for institutionalization or disability.

62 ICPSR \# 7756 (1960), ICPSR \# 18 (1970), ICPSR \#8101 (1980).
} 
The estimation samples dropped children living in group quarters and observations were any of the following variables were allocated for the child - age (all years), race (1970 and 1980 only), and place of birth (1970 and 1980 only).

\section{OCTOBER CPS MICRODATA}

Microdata underlying estimates in columns (1)-(6) of Table V were drawn from the 1968 through 1983 October CPS School Enrollment Supplements. ${ }^{63}$ Samples include all surveyed white and black five year olds who resided in one of 11 regions defined below. Final survey weights were used in calculating region-by-year specific enrollment rates. Final survey weights were also used to estimate the population of five year olds residing in each state between 1977 and 1983. This population estimate was used to generate the population-weighted fraction of states in a region with funding for kindergarten.

Prior to 1977, state of residence is not reported for all respondents. Instead, residence is reported for groups of states, with different groups defined over the periods 1968 to 1972 and 1973 to 1976 . So that the unit of observation would remain the same over 1968-83, I collapsed the data to averages for 11 geographic regions consistently observed over the sample period (treated states are in bold): (1) Delaware, Maryland, Virginia, West Virginia; (2) Georgia, North Carolina, South Carolina; (3) Florida; (4) Kentucky, Tennessee; (5) Alabama, Mississippi; (6) Texas; (7) Arkansas, Louisiana, Oklahoma; (8) Arizona, Colorado, Idaho, Montana, Nevada, New Mexico, Utah, Wyoming; and (9) Alaska, Hawaii, Oregon, and Washington; (10) Maine, Massachusetts, New Hampshire, Rhode Island, Vermont; (11) Iowa, Kansas, Minnesota, Missouri, Nebraska, North Dakota, South Dakota. I define three broader regions based on 1964-65 spending per pupil: low (regions 2, 4, 5, and 7), medium (regions 3, 6, and 10), and high (regions 1, 8, 9, and 11). Interactions of indicators for these regions with year are included in the regressions presented in Table $\mathrm{V}$.

School enrollment indicators in the microdata were constructed from responses to three questions consistently asked over the sample period: (1) whether a child is currently enrolled in school; (2) if enrolled, whether the school is public or private; and (3) if enrolled, the grade of enrollment. The third question also designates length of day (full or part) for nursery school and kindergarten; I assume that if enrolled in grade 1 or higher, enrollment is full day. Children not enrolled in school were coded as zeroes for all binary enrollment variables; children enrolled in private (public) school were coded as zeroes for all binary enrollment variables pertaining to public (private) enrollment.

\section{PSID MICRODATA}

Microdata underlying estimates in last column of Table V were drawn from the PSID. ${ }^{64}$ The sample includes individuals with non-missing responses to the Head Start survey questions

\footnotetext{
${ }^{63}$ Data were downloaded from ICPSR. Relevant studies are \#9546 (1968), \#9547 (1969), \#9544 (1970), \#9545 (1971), \#9542 (1972), \#9541 (1973), \#9543 (1974), \#9539 (1975), \#9540 (1976), \#9538 (1977), \#9537 (1978), \#9536 (1979), \#9535 (1980), \#8116 (1981), \#9534 (1982), and \#8361 (1983).

${ }^{64}$ Data were downloaded from ICPSR. Relevant studies are \#9546 (1968), \#9547 (1969), \#9544 (1970), \#9545 (1971), \#9542 (1972), \#9541 (1973), \#9543 (1974), \#9539 (1975), \#9540 (1976), \#9538 (1977), \#9537 (1978), \#9536 (1979), \#9535 (1980), \#8116 (1981), \#9534 (1982), and \#8361 (1983).
} 
in 1995 who were aged five by the end of the third quarter 1968 through 1983, who resided in a treated CPS region (see Section IV of this Appendix) at this time, and who were from families classified as black or white in the 1968 interview. ${ }^{65}$ An individual was classified as having attended Head Start at age five if he: (1) first attended Head Start at age five; (2) first attended Head Start at age four and was enrolled for at least one year; or (3) first attended Head Start at age three and was enrolled for at least two years. I use 1995 interview weights to collapse this indicator to a CPS region-cohort-race average.

65 The universe for the 1995 Head Start questions excludes individuals from the Immigrant sample; individuals whose main family did not respond by 1995; individuals who moved in after the 1995 interview; individuals aged 40 or over; and individuals who never attended school. For individuals turning age five by end of third quarter 1968 or 1969, I assign state of residence as of 1970, the first year in which it is reported. 


\section{REFERENCES}

Alabama Department of Education. 1977. Public Kindergarten Pilot Program in Alabama: A Progress Report, 1973-76. Montgomery, AL: State Department of Education.

Almond, Douglas. 2006. "Is the 1918 Influenza Pandemic Over? Long-term Effects of In Utero Influenza Exposure in the Post-1940 U.S. Population.” Journal of Political Economy 114(August): 672-712.

Anderson, Michael. 2008. "Multiple Inference and Gender Differences in the Effects of Early Intervention: A Reevaluation of the Abecedarian, Perry Preschool, and Early Training Projects." Journal of the American Statistical Association 103(484): 1481-1495.

Ashenfelter, Orley, William J. Collins, and Albert Yoon. 2006. "Evaluating the Role of Brown v. Board of Education in School Equalization, Desegregation, and the Income of African Americans." American Law and Economics Review 8(2): 213-248.

Baker, Michael, Jonathan Gruber, and Kevin Milligan. 2008. "Universal Childcare, Maternal Labor Supply, and Family Well-Being." Journal of Political Economy 116(4): 709-745.

Barnett, W. Steven. 1998. "Long-Term Effects on Cognitive Development and School Success." In Early Care and Education For Children in Poverty: Promises, Programs, and Long-Term Results, eds. W. Steven Barnett and Sarane Spence Boocock, 11-44. Albany, NY: SUNY Press.

Beatty, Barbara. 1995. Preschool Education in America: The Culture of Young Children from the Colonial Era to the Present. New Haven: Yale University Press.

Berlinski, Samuel, Sebastian Galiani, and Paul Gertler. 2009. “The Effect of Pre-Primary Education on Primary School Performance.” Journal of Public Economics 93: 219-234.

Bertrand, Marianne, Esther Duflo, and Sendhil Mullainathan. 2004. "How Much Should We Trust Differences-in-Differences Estimates?” Quarterly Journal of Economics 119(1): 249275.

Blau, David and Janet Currie. 2006. "Preschool, Day Care, and After School Care: Who's Minding the Kids?" In Handbook of the Economics of Education, Volume 2, ed. Eric Hanushek and Finis Welch, 1163-1278. The Netherlands: Elsevier.

Borjas, George J., Jeffrey Grogger, and Gordon H. Hanson. 2007. "Immigration and AfricanAmerican Employment Opportunities: The Response of Wages, Employment, and Incarceration to Labor Supply Shocks.” NBER Working Paper 12518. Cambridge, MA: NBER.

Butcher, Kristin F. and Anne Morrison Piehl. 2005. “Why are Immigrants' Incarceration Rates So Low? Evidence on Selective Immigration, Deterrence, and Deportation.” Federal Reserve Bank of Chicago Working Paper 2005-19. 
Cameron, A. Colin, Jonah B. Gelbach, and Douglas L. Miller. 2008. "Bootstrapped-Based Improvements for Inference with Clustered Errors." The Review of Economics and Statistics 90(3): 414-427.

Card, David and Alan B. Krueger. 1992. "School Quality and Black-White Relative Earnings: A Direct Assessment," Quarterly Journal of Economics, 107(1): 151-200.

Cascio, Elizabeth U. 2004. "Schooling Attainment and the Introduction of Kindergartens into Public Schools.” Mimeo, University of California, Davis.

----. 2005. "School Progression and the Grade Distribution of Students: Evidence from the Current Population Survey." IZA Discussion Paper 1747. Bonn, Germany: Institute for the Study of Labor.

----. 2009. "Maternal Labor Supply and the Introduction of Kindergartens into American Public Schools." Journal of Human Resources 44(1): 140-170.

Chapman, Hiram R. 1975. A Conceptual Framework and Implementation Plan for the Anticipated Expansion of the Alabama Kindergarten Program. Ph.D. Dissertation, University of Alabama.

Currie, Janet. 2001. "Early Childhood Education Programs." Journal of Economic Perspectives, 15(2), 213-238.

Currie, Janet and Duncan Thomas. 1995. "Does Head Start Make a Difference?” American Economic Review, 85(3): 341-364.

Dean, Stuart E. 1960. Elementary School Administration and Organization: A National Survey of Policies and Practices. Washington, DC: U.S. GPO.

Education Commission of the States. 1971a. Early Childhood Development: Alternatives for Program Implementation in the States. Denver, CO: ECS.

---- 1971b. Legislation, Achievements and Problems in Education: A Survey of the States, 1971. Denver, CO: ECS. (ERIC No. ED048406).

---. 1972. Legislation, Achievements and Problems in Education: A Survey of the States, 1972. Revised. Denver, CO: ECS. (ERIC No. ED063662).

----. 1973. Early Childhood Planning in the States: A Handbook for Gathering Data and Assessing Needs. Denver, CO: ECS.

----. 1974a. 1973 State Education Legislation and Activity: Curriculum, Instruction and Special Programs: A Survey of the States. Denver, CO: ECS. (ERIC No. ED093034).

----. 1974b. 1973 State Education Legislation and Activity: Schools, Students, and Services: A Survey of the States. Denver, CO: ECS. (ERIC No. ED091837). 
----. 1974c. 1973 State Education Legislation and Activity: School Finance: A Survey of the States.

Denver, CO: ECS. (ERIC No. ED091835).

----. 1974d. 1973 State Education Legislation and Activity: General Governance and Administration: A Survey of the States. Denver, CO: ECS. (ERIC No. ED089473).

----. 1975a. Early Childhood Programs: A State Survey 1974-1975. Denver, CO: ECS.

---- 1975b. The Very Young and Education: 1974 State Activity. Denver, CO: ECS.

----. 1976. 1975 State Education Legislation: A Survey of the States. Denver, CO: ECS. (ERIC No. ED131541)

Fitzpatrick, Maria D. 2008. "Preschoolers Enrolled and Mothers at Work? The Effects of Universal Pre-Kindergarten.” Mimeo, Stanford University.

Forgione, Pascal D. 1977. The Politics of Early Education Legislation: Three Comparative Case Studies. Ph.D. Dissertation, Stanford University.

Garces, Eliana, Duncan Thomas, and Janet Currie. 2002. "Longer Term Effects of Head Start." American Economic Review 92(4): 999-1012.

Gormley, William T. and Ted Gayer. 2005. "Promoting School Readiness in Oklahoma: An Evaluation of Tulsa's Pre-K Program.” Journal of Human Resources 40(3): 533-558.

Harris, Delores M. 1987. The Origins and Development of Public Kindergarten Policy in the State of Maryland: Selected Jurisdictions. Ph.D. Dissertation, University of Maryland College Park.

Heckman, James and Dimitriy Masterov. 2007. "The Productivity Argument for Investing in Young Children.” NBER Working Paper 13016. Cambridge, MA: NBER.

Hirsch, Barry T. and Edward J. Schumacher. 2004. "Match Bias in Wage Gap Estimates Due to Earnings Imputation.” Journal of Labor Economics 22(3): 689-722.

Jones, Janie L. 1977. Kentucky's Kindergarten Program: Four Years Later. Frankfort, KY: Kentucky Legislative Research Commission. (Research Report No. 132).

Jones, Jean Yavis. 1979. The Head Start Program - History, Legislation, Issues and Funding 1964-1978. Washington, D.C.: Congressional Research Service. Report 79-14 EPW.

Kanensiger, Andy. 1983. "Mississippi Votes 'Monumental' Reforms in Education Programs." Education Week (January 12, 1983).

Karoly, Lynn A., Peter W. Greenwood, Susan S. Everingham, Jill Hoube, M. Rebecca Kilburn, C. Peter Rydell, Matthew Sanders, and James Chiesa. 1997. Investing in Our Children: What We Know and Don't Know About the Costs and Benefits of Early Childhood Interventions. Santa Monica: RAND. 
Krueger, Alan B. and Diane M. Whitmore. 2002. "Would Smaller Classes Help Close the BlackWhite Achievement Gap?" In Bridging the Achievement Gap, ed. John E. Chubb and Tom Loveless, 11-46. Washington, D.C.: The Brookings Institution.

Lightfoot, Bobbye K. 1982. A History of the Development of State-Funded Kindergartens in Alabama. Ed.D. Dissertation, University of Alabama.

Lochner, Lance, and Enrico Moretti. 2004. "The Effect of Education on Crime: Evidence from Prison Inmates, Arrests, and Self-Reports.” American Economic Review 94(1): 155-189.

Ludwig, Jens and Douglas L. Miller. 2007. "Does Head Start Improve a Children's Life Chances? Evidence from a Regression Discontinuity Design.” Quarterly Journal of Economics 122(1): 159-208.

Murray, Rebecca J. 1973. The Development of the Kindergarten Program in the Public School System of North Carolina. Ed.D. Dissertation, Duke University.

National Education Association. 1962. Kindergarten Practices, 1961. Washington, DC: the Association.

----. 1966. High Spots in State School Legislation, Jan. 1 - Aug. 1 1966. Washington, DC: the Association. (ERIC No. ED024152).

----. 1967. High Spots in State School Legislation, Jan. 1 - Aug. 31 1967. Washington, DC: the Association. (ERIC No. ED024153).

---. 1968. High Spots in State School Legislation, January 1 - August 31, 1968. Washington, DC: the Association. (ERIC No. ED030214).

----. 1969. Kindergarten Education in Public Schools. Washington DC: the Association.

---. 1971. High Spots in States School Legislation, January 1 - August 31, 1971. Washington, DC: the Association. (ERIC No. ED059539).

----. 1972. High Spots in States School Legislation, January 1 - August 31, 1972. Washington, DC: the Association. (ERIC No. ED067778).

----. 1973. High Spots in States School Legislation, January 1 - August 31, 1973. Washington, DC: the Association. (ERIC No. ED120982).

Oreopoulos, Philip, Marianne E. Page, and Ann Huff Stevens. 2006. "The Intergenerational Effects of Compulsory Schooling." Journal of Labor Economics 24(4): 729-760.

Reber, Sarah. 2007. “Desegregation and Educational Attainment for Blacks.” NBER Working Paper 13193. Cambridge, MA: NBER.

Tanner, Laurel N. and Daniel Tanner. 1973. "Unanticipated Effects of Federal Policy: the Kindergarten.” Educational Leadership 31(1): 49-52. 
Texas State Department of Community Affairs. 1972. Early Childhood Development in Texas: 1972. Austin: Office of Early Childhood Development. (ERIC No. ED072867).

U.S. Department of Education, Office of Education. 1963a. Public School Finance Programs, 196162. Washington, DC: U.S. GPO.

----. 1963b. Public School Finance Programs, 1962-63. Washington, DC: U.S. GPO.

---- 1967. Public School Finance Programs, 1966-67. Washington, DC: U.S. GPO.

---. 1968. Statistical Report Fiscal Year 1967: Title I/ Year II. Washington, DC: U.S. GPO.

----. 1969. Public School Finance Programs, 1968-69. Washington, DC: U.S. GPO.

---. 1972. Public School Finance Programs, 1971-72. Washington, DC: U.S. GPO.

----. 1976. Public School Finance Programs, 1975-76. Washington, DC: U.S. GPO.

----. 1980. Public School Finance Programs, 1978-79. Washington, DC: U.S. GPO.

U.S. Department of Health, Education, and Welfare, Administration for Children, Youth and Families Office of Human Development Services. 1980b. Project Head Start Statistical Fact Sheet. Washington, D.C.: U.S. GPO (February).

U.S. Department of Health and Human Services, Administration for Children, Youth, and Families, Office of Human Development Services. 1990. Project Head Start Statistical Fact Sheet. Washington, D.C.: U.S. GPO (January).

U.S. Department of Health and Human Services, Administration for Children and Families. 2008. Head Start Program Fact Sheet. Washington, D.C.: U.S. GPO (February).

U.S. Senate. Committee on Labor and Public Welfare, Subcommitee on Education. 1965. Maximum Basic Grants - Elementary and Secondary Education Act of 1965 (Public Law 81-874, Title II, and Public Law 89-10, Title I). Washington, DC: US GPO (September).

Watson, Jeanette and Fritz Lanham. 1971. Early Childhood Development in Texas. Special Report. Austin: Texas State Department of Community Affairs, Office of Early Childhood Development. (ERIC No. ED067145).

West, Jerry, Kristin Denton, and Elvira Germino-Hausken. 2000. America's Kindergartners. Washington, D.C.: U.S. Department of Education, National Center for Education Statistics. (NCES 2000-070).

Zigler, Edward F. and Susan Muenchow 1992. Head Start: The Inside Story of America's Most Successful Educational Experiment. New York: Basic Books. 
Table I. State Funding Initiatives for Kindergarten after 1960

\begin{tabular}{cccc}
\hline \hline & & Region & Other \\
\cline { 2 - 4 } Year of Adoption & South & West & \\
1966 & & AK & NH \\
1967 & MD, MO & & \\
1968 & DE, FL, VA & & \\
1969 & OK & AZ & \\
1971 & WV & OR & \\
1973 & AR, NC, SC, TN, TX & MT & \\
1974 & & NM, ID & ND \\
1975 & & & \\
1977 & AL, KY & & \\
1978 & GA & & \\
1980 & & & \\
1983 & MS & & \\
& & & \\
\hline
\end{tabular}

Notes: Year of adoption corresponds to the first year in which state funds for kindergarten were available to all districts in the state, either through application or entitlement. The South includes all states in the Southern census divisions, plus Missouri. The West consists of all states in the Western census divisions. See Appendix for sources. 


\section{Table II. State Kindergarten Funding, Kindergarten Supply, and Public School}

Kindergarten Enrollment

\begin{tabular}{|c|c|c|}
\hline & $(1)$ & $(2)$ \\
\hline & \multicolumn{2}{|c|}{ A. Fraction of School Districts Offering $\mathrm{K}$} \\
\hline Pre-initiative Mean & \multicolumn{2}{|c|}{0.153} \\
\hline \multicolumn{3}{|l|}{ Coefficient (standard error) on: } \\
\hline Post-initiative dummy & $\begin{array}{c}0.336 * * * \\
(0.092)\end{array}$ & $\begin{array}{c}0.165^{* *} \\
(0.073)\end{array}$ \\
\hline Linear trend in normalized year & & $\begin{array}{c}0.056^{* *} \\
(0.021)\end{array}$ \\
\hline Post-initiative trend break & & $\begin{array}{l}-0.017 \\
(0.025)\end{array}$ \\
\hline R-squared & 0.86 & 0.87 \\
\hline \multirow[t]{2}{*}{$\mathrm{N}$} & \multicolumn{2}{|c|}{432} \\
\hline & \multicolumn{2}{|c|}{ B. K/1st Enrollment } \\
\hline Pre-initiative Mean & \multicolumn{2}{|c|}{0.146} \\
\hline \multicolumn{3}{|l|}{ Coefficient (standard error) on: } \\
\hline Post-initiative dummy & $\begin{array}{c}0.340^{* * *} \\
(0.048)\end{array}$ & $\begin{array}{c}0.231 * * * \\
(0.029)\end{array}$ \\
\hline Linear trend in normalized year & & $\begin{array}{c}0.020 * * \\
(0.008)\end{array}$ \\
\hline Post-initiative trend break & & $\begin{array}{c}0.020 \\
(0.015)\end{array}$ \\
\hline R-squared & 0.91 & 0.92 \\
\hline $\mathrm{N}$ & & \\
\hline
\end{tabular}

Notes: Each column and panel represents a different regression. Each regression includes state fixed effects, year $\mathrm{x}$ education spending group of state fixed effects (see text), and year x Southern region fixed effects. Regressions in column (2) also include indicators set to one if the survey year was 7 or more years prior to or 7 or more years after a state initiative. Samples include treated states only (Table I), and standard errors are clustered on state (24 clusters). Critical values are drawn from a tdistribution with 22 degrees of freedom. ${ }^{* * *}$, **, and $*$ indicate significance at the $1 \%, 5 \%$, and $10 \%$ levels, respectively.

Sources: Fraction of School Districts Offering Kindergarten (fall of years 1962-63, 1965-69, 1971-72, 1974-82): Education Directory, Elementary and Secondary General Information Survey, Common Core of Data (CCD) Local Education Agency Surveys. K/1st Enrollment (fall of years 1959, 1961-83): CCD State Non-Fiscal Survey and and published tabulations of the Office of Education Surveys that preceded it. See Appendix for more details. 
Table III. State Kindergarten Funding and Child and Adult Outcomes, by Race

\begin{tabular}{|c|c|c|c|c|c|c|c|c|c|}
\hline & $\underline{\text { Grade Retent }}$ & $n$ and Educatic & al Attainment: & & Employment & id Earnings: & Other: & & \\
\hline Dependent variable: & $\begin{array}{l}\text { Below Grade } \\
\text { for Age } \\
(1)\end{array}$ & $\begin{array}{l}\text { High School } \\
\text { Dropout } \\
(2)\end{array}$ & $\begin{array}{l}\text { High School } \\
\text { Degree Only } \\
\text { (3) }\end{array}$ & $\begin{array}{l}\text { Some College } \\
(4)\end{array}$ & $\begin{array}{l}\text { Worked Last } \\
\text { Year } \\
(5)\end{array}$ & $\begin{array}{l}\ln (\text { Earnings } \\
\left.\text { Last Year, } \$^{\prime} 07\right) \\
(6)\end{array}$ & $\begin{array}{l}\text { Any Public } \\
\text { Assistance } \\
\text { (7) }\end{array}$ & $\begin{array}{l}\text { Reside in } \\
\text { Institution } \\
(8)\end{array}$ & $\begin{array}{l}\text { Employment } \\
\text { Disability } \\
(9)\end{array}$ \\
\hline & & & A. & aites Born in Sta & es with Kinder & Irten Funding Ini & tiatives & & \\
\hline Pre-initiative mean & 0.220 & 0.154 & 0.344 & 0.502 & 0.872 & 9.96 & 0.0248 & 0.0073 & 0.0563 \\
\hline Coefficient (standard error) on: & & & & & & & & & \\
\hline Post-initiative dummy & $\begin{array}{l}-0.0016 \\
(0.0058)\end{array}$ & $\begin{array}{c}-0.0038^{*} \\
(0.0018)\end{array}$ & $\begin{array}{l}-0.0027 \\
(0.0038)\end{array}$ & $\begin{array}{c}0.0065^{*} \\
(0.0035)\end{array}$ & $\begin{array}{l}-0.0000 \\
(0.0012)\end{array}$ & $\begin{array}{l}0.0080 \\
(0.0070)\end{array}$ & $\begin{array}{l}-0.0001 \\
(0.0007)\end{array}$ & $\begin{array}{l}-0.0016^{\text {*** }} \\
(0.0004)\end{array}$ & $\begin{array}{c}-0.0026^{*} \\
(0.0014)\end{array}$ \\
\hline Linear trend in normalized year & $\begin{array}{c}-0.0052 * \\
(0.0026)\end{array}$ & $\begin{array}{l}-0.0005 \\
(0.0008)\end{array}$ & $\begin{array}{l}0.0032^{* *} \\
(0.0012)\end{array}$ & $\begin{array}{c}-0.0027^{*} \\
(0.0014)\end{array}$ & $\begin{array}{l}-0.0004 \\
(0.0006)\end{array}$ & $\begin{array}{l}0.0033 \\
(0.0033)\end{array}$ & $\begin{array}{l}-0.0002 \\
(0.0003)\end{array}$ & $\begin{array}{l}0.0001 \\
(0.0002)\end{array}$ & $\begin{array}{l}0.0001 \\
(0.0003)\end{array}$ \\
\hline Post-initiative trend break & $\begin{array}{l}0.0027 \\
(0.0021)\end{array}$ & $\begin{array}{l}0.0002 \\
(0.0010)\end{array}$ & $\begin{array}{l}-0.0009 \\
(0.0006)\end{array}$ & $\begin{array}{l}0.0007 \\
(0.0010)\end{array}$ & $\begin{array}{c}0.0013^{*} \\
(0.0006)\end{array}$ & $\begin{array}{l}-0.0017 \\
(0.0022)\end{array}$ & $\begin{array}{l}0.0001 \\
(0.0002)\end{array}$ & $\begin{array}{l}-0.0002 \\
(0.0001)\end{array}$ & $\begin{array}{l}0.0004 \\
(0.0004)\end{array}$ \\
\hline R-squared & 0.91 & 0.92 & 0.95 & 0.97 & 0.84 & 0.98 & 0.81 & 0.38 & 0.91 \\
\hline $\mathrm{N}$ & 480 & 840 & 840 & 840 & 840 & 840 & 840 & 840 & 840 \\
\hline & & & B. 1 & acks Born in Sta & es with Kinder & rten Funding Ini & iatives & & \\
\hline Pre-initiative mean & 0.313 & 0.23 & 0.381 & 0.389 & 0.797 & 9.67 & 0.0898 & 0.0295 & 0.0815 \\
\hline Coefficient (standard error) on: & & & & & & & & & \\
\hline Post-initiative dummy & $\begin{array}{l}0.0021 \\
(0.0110)\end{array}$ & $\begin{array}{l}0.0075 \\
(0.0048)\end{array}$ & $\begin{array}{l}0.0002 \\
(0.0072)\end{array}$ & $\begin{array}{l}-0.0077 \\
(0.0067)\end{array}$ & $\begin{array}{l}-0.0076 \\
(0.0060)\end{array}$ & $\begin{array}{l}-0.0075 \\
(0.0208)\end{array}$ & $\begin{array}{l}0.0017 \\
(0.0041)\end{array}$ & $\begin{array}{l}0.0007 \\
(0.0024)\end{array}$ & $\begin{array}{l}0.0012 \\
(0.0039)\end{array}$ \\
\hline Linear trend in normalized year & $\begin{array}{l}-0.0037 \\
(0.0040)\end{array}$ & $\begin{array}{l}0.0004 \\
(0.0017)\end{array}$ & $\begin{array}{l}-0.0006 \\
(0.0017)\end{array}$ & $\begin{array}{l}0.0003 \\
(0.0017)\end{array}$ & $\begin{array}{l}0.0016 \\
(0.0023)\end{array}$ & $\begin{array}{l}0.0097 * * \\
(0.0040)\end{array}$ & $\begin{array}{l}0.0011 \\
(0.0011)\end{array}$ & $\begin{array}{l}-0.0005 \\
(0.0006)\end{array}$ & $\begin{array}{l}0.0012 \\
(0.0009)\end{array}$ \\
\hline Post-initiative trend break & $\begin{array}{l}0.0114 * * \\
(0.0041)\end{array}$ & $\begin{array}{l}0.0027 \\
(0.0020)\end{array}$ & $\begin{array}{l}0.0020 \\
(0.0015)\end{array}$ & $\begin{array}{l}-0.0047 * * \\
(0.0017)\end{array}$ & $\begin{array}{l}-0.0009 \\
(0.0031)\end{array}$ & $\begin{array}{l}-0.0001 \\
(0.0041)\end{array}$ & $\begin{array}{l}0.0002 \\
(0.0010)\end{array}$ & $\begin{array}{l}-0.0007^{*} \\
(0.0004)\end{array}$ & $\begin{array}{l}-0.0014 \\
(0.0010)\end{array}$ \\
\hline R-squared & 0.90 & 0.79 & 0.78 & 0.87 & 0.81 & 0.96 & 0.81 & 0.53 & 0.89 \\
\hline $\mathrm{N}$ & 447 & 826 & 826 & 826 & 825 & 818 & 824 & 827 & 827 \\
\hline $\begin{array}{l}p \text {-value: black }=\text { white coefficient } \\
\text { on post-initiative dummy }\end{array}$ & 0.715 & 0.0430 & 0.703 & 0.0358 & 0.196 & 0.461 & 0.651 & 0.333 & 0.365 \\
\hline
\end{tabular}

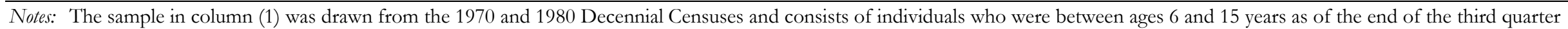

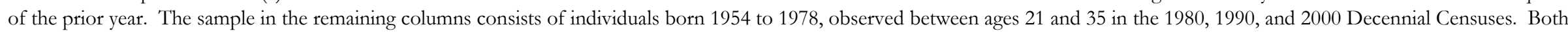

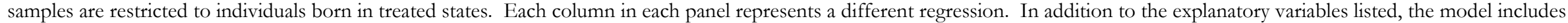

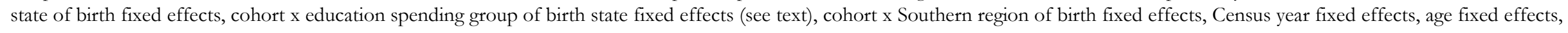

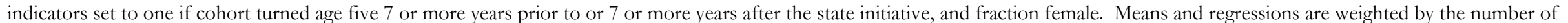

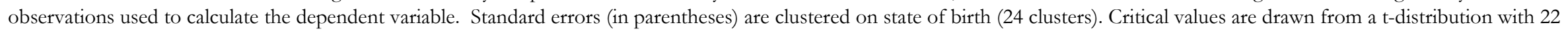
degrees of freedom. ${ }^{* * *}, * *$, and $*$ indicate significance at the $1 \%, 5 \%$, and $10 \%$ levels, respectively. 
Table IV. State Kindergarten Funding and Outcomes, by Race: Alternative Specifications and Samples

\begin{tabular}{|c|c|c|c|c|c|c|c|c|c|c|}
\hline & Dependent variable: & $\begin{array}{l}\text { Grade Retent } \\
\text { Below Grade } \\
\text { for Age } \\
\text { (1) }\end{array}$ & $\begin{array}{l}\text { n and Educatic } \\
\text { High School } \\
\text { Dropout } \\
\text { (2) }\end{array}$ & $\begin{array}{l}\text { al Attainment: } \\
\text { High School } \\
\text { Degree Only } \\
\text { (3) }\end{array}$ & $\begin{array}{l}\text { Some College } \\
\text { (4) }\end{array}$ & $\begin{array}{l}\text { Employment } \\
\text { Worked Last } \\
\text { Year } \\
(5)\end{array}$ & $\begin{array}{l}\text { ad Earnings: } \\
\ln \text { (Earnings } \\
\text { Last Year) } \\
\text { (6) }\end{array}$ & $\begin{array}{l}\text { Other: } \\
\text { Any Public } \\
\text { Assistance } \\
\text { (7) }\end{array}$ & $\begin{array}{l}\text { Reside in } \\
\text { Institution } \\
(8)\end{array}$ & $\begin{array}{l}\text { Employment } \\
\text { Disability } \\
(9)\end{array}$ \\
\hline & & \multicolumn{9}{|c|}{ A. Whites Born in States with Kindergarten Funding Initiatives } \\
\hline 1. & Baseline & $\begin{array}{l}-0.0016 \\
(0.0058)\end{array}$ & $\begin{array}{c}-0.0038^{*} \\
(0.0018)\end{array}$ & $\begin{array}{l}-0.0027 \\
(0.0038)\end{array}$ & $\begin{array}{l}0.0065 * \\
(0.0035)\end{array}$ & $\begin{array}{l}-0.0000 \\
(0.0012)\end{array}$ & $\begin{array}{l}0.0080 \\
(0.0070)\end{array}$ & $\begin{array}{l}-0.0001 \\
(0.0007)\end{array}$ & $\begin{array}{l}-0.0016^{* * *} \\
(0.0004)\end{array}$ & $\begin{array}{c}-0.0026^{*} \\
(0.0014)\end{array}$ \\
\hline 2. & Add family background & $\begin{array}{l}-0.0003 \\
(0.0058)\end{array}$ & $\begin{array}{l}-0.0040^{*} \\
(0.0021)\end{array}$ & $\begin{array}{l}-0.0033 \\
(0.0038)\end{array}$ & $\begin{array}{l}0.0073 * * \\
(0.0032)\end{array}$ & $\begin{array}{l}-0.0001 \\
(0.0012)\end{array}$ & $\begin{array}{l}0.0097 \\
(0.0081)\end{array}$ & $\begin{array}{l}-0.0000 \\
(0.0008)\end{array}$ & $\begin{array}{l}-0.0015^{* * *} \\
(0.0004)\end{array}$ & $\begin{array}{l}-0.0034 * * \\
(0.0013)\end{array}$ \\
\hline 3. & Add state unemp rate at age 20 & - & $\begin{array}{l}-0.0041 * * \\
(0.0019)\end{array}$ & $\begin{array}{l}-0.0038 \\
(0.0036)\end{array}$ & $\begin{array}{l}0.0080^{* *} \\
(0.0036)\end{array}$ & $\begin{array}{l}0.0003 \\
(0.0012)\end{array}$ & $\begin{array}{l}0.0003 \\
(0.0069)\end{array}$ & $\begin{array}{l}-0.0000 \\
(0.0008)\end{array}$ & $\begin{array}{l}-0.0015^{* * *} \\
(0.0005)\end{array}$ & $\begin{array}{l}-0.0026^{*} \\
(0.0015)\end{array}$ \\
\hline 4. & Add state-specific cohort trends & $\begin{array}{l}0.0024 \\
(0.0061)\end{array}$ & $\begin{array}{l}-0.0037^{*} \\
(0.0020)\end{array}$ & $\begin{array}{l}-0.0030 \\
(0.0038)\end{array}$ & $\begin{array}{l}0.0068 * \\
(0.0035)\end{array}$ & $\begin{array}{l}-0.0001 \\
(0.0013)\end{array}$ & $\begin{array}{l}0.0094 \\
(0.0072)\end{array}$ & $\begin{array}{l}-0.0002 \\
(0.0007)\end{array}$ & $\begin{array}{l}-0.0015^{* * *} \\
(0.0004)\end{array}$ & $\begin{array}{c}-0.0026^{*} \\
(0.0015)\end{array}$ \\
\hline & $\begin{array}{l}\text { Add cohort } x \text { spending group } x \\
\text { South fixed effects }\end{array}$ & $\begin{array}{l}-0.0019 \\
(0.0064)\end{array}$ & $\begin{array}{l}-0.0039 * \\
(0.0019)\end{array}$ & $\begin{array}{l}-0.0016 \\
(0.0042)\end{array}$ & $\begin{array}{l}0.0055 \\
(0.0037)\end{array}$ & $\begin{array}{l}-0.0005 \\
(0.0013)\end{array}$ & $\begin{array}{l}0.0098 \\
(0.0069)\end{array}$ & $\begin{array}{l}-0.0003 \\
(0.0008)\end{array}$ & $\begin{array}{l}-0.0017 * * * \\
(0.0004)\end{array}$ & $\begin{array}{l}-0.0017 \\
(0.0014)\end{array}$ \\
\hline & South only $(n=560)$ & $\begin{array}{l}-0.0046 \\
(0.0067) \\
\{0.226\}\end{array}$ & $\begin{array}{l}-0.0035 \\
(0.0021) \\
\{0.161\}\end{array}$ & $\begin{array}{l}-0.0014 \\
(0.0046) \\
\{0.346\}\end{array}$ & $\begin{array}{l}0.0048 \\
(0.0040) \\
\{0.492\}\end{array}$ & $\begin{array}{l}-0.0003 \\
(0.0013) \\
\{0.870\}\end{array}$ & $\begin{array}{l}0.0098 \\
(0.0075) \\
\{9.97\}\end{array}$ & $\begin{array}{l}-0.0001 \\
(0.0009) \\
\{0.0238\}\end{array}$ & $\begin{array}{l}-0.0018^{* * *} \\
(0.0005) \\
\{0.0073\}\end{array}$ & $\begin{array}{l}-0.0013 \\
(0.0016) \\
\{0.0561\}\end{array}$ \\
\hline & Males only & $\begin{array}{l}0.0034 \\
(0.0083) \\
\{0.266\}\end{array}$ & $\begin{array}{l}-0.0028^{*} \\
(0.0016) \\
\{0.168\}\end{array}$ & $\begin{array}{c}-0.0007 \\
(0.0039) \\
\{0.348\}\end{array}$ & $\begin{array}{l}0.0034 \\
(0.0036) \\
\{0.484\}\end{array}$ & $\begin{array}{l}0.0000 \\
(0.0023) \\
\{0.948\}\end{array}$ & $\begin{array}{l}0.0012 \\
(0.0101) \\
\{10.220\}\end{array}$ & $\begin{array}{l}-0.0001 \\
(0.0008) \\
\{0.0143\}\end{array}$ & $\begin{array}{l}-0.0029^{* * *} \\
(0.0009) \\
\{0.0122\}\end{array}$ & $\begin{array}{l}-0.0013 \\
(0.0022) \\
\{0.0645\}\end{array}$ \\
\hline & Females only & $\begin{array}{l}-0.0068 \\
(0.0046) \\
\{0.173\}\end{array}$ & $\begin{array}{l}-0.0047 \\
(0.0031) \\
\{0.140\}\end{array}$ & $\begin{array}{l}-0.0046 \\
(0.0050) \\
\{0.340\}\end{array}$ & $\begin{array}{l}0.0094^{*} \\
(0.0048) \\
\{0.520\}\end{array}$ & $\begin{array}{l}-0.0001 \\
(0.0026) \\
\{0.797\}\end{array}$ & $\begin{array}{l}0.0145 \\
(0.0097) \\
\{9.670\}\end{array}$ & $\begin{array}{l}-0.0000 \\
(0.0014) \\
\{0.0352\}\end{array}$ & $\begin{array}{l}-0.0002 \\
(0.0003) \\
\{0.0024\}\end{array}$ & $\begin{array}{l}-0.0039 * \\
(0.0021) \\
\{0.0482\}\end{array}$ \\
\hline
\end{tabular}


Table IV. Kindergarten Funding and Outcomes, by Race: Alternative Specifications and Samples (Cont'd)

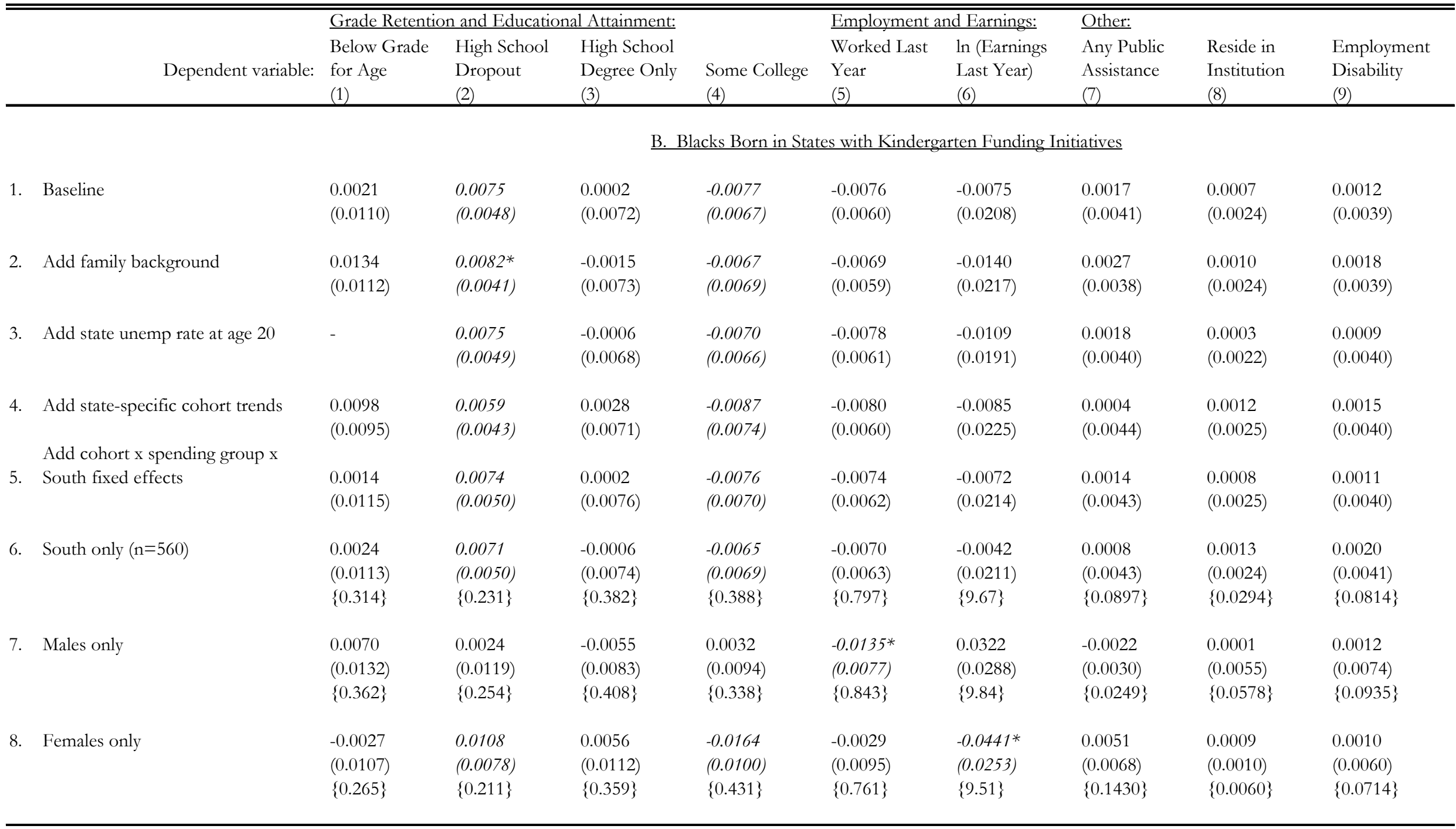

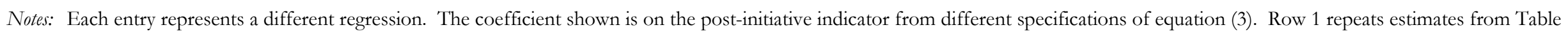

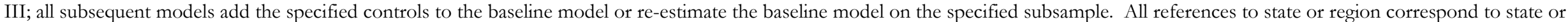

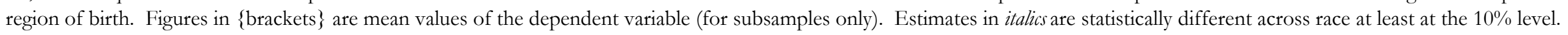

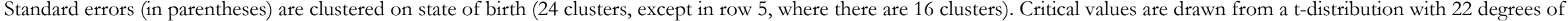
freedom (rows 1-4, 6-8) or 14 degrees of freedom (row 5). ***, **, and * indicate significance at the 1\%, $5 \%$, and $10 \%$ levels, respectively. 
Table V. Alternative Hypotheses: The Effects of State Kindergarten Funding on Crowd Out of Enrollment in Other Early Education and Length of the Kindergarten Day, by Race

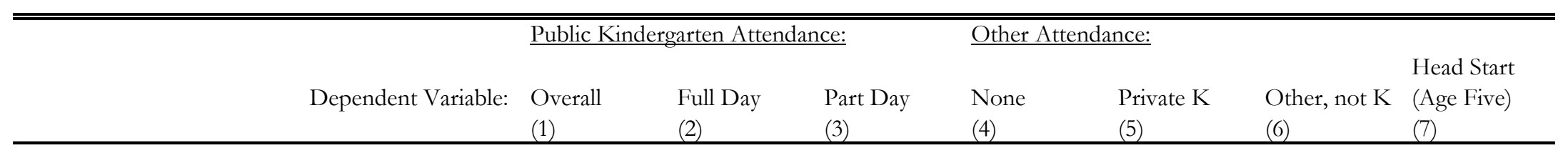

A. Whites Residing in CPS Region with Treated State(s)

\begin{tabular}{|c|c|c|c|c|c|c|c|}
\hline Mean & 0.590 & 0.134 & 0.457 & 0.165 & 0.141 & 0.104 & 0.0194 \\
\hline \multicolumn{8}{|l|}{ Coefficient (se) on: } \\
\hline \multirow[t]{2}{*}{ Post-initiative share (population weighted) } & $0.273^{* * *}$ & 0.051 & $0.223 * *$ & $-0.135^{* * *}$ & $-0.097 * * *$ & -0.042 & 0.005 \\
\hline & $(0.060)$ & $(0.060)$ & $(0.086)$ & $(0.036)$ & $(0.019)$ & $(0.033)$ & $(0.045)$ \\
\hline R-squared & 0.95 & 0.89 & 0.94 & 0.95 & 0.88 & 0.69 & 0.45 \\
\hline $\mathrm{N}$ & 176 & 176 & 176 & 176 & 176 & 176 & 174 \\
\hline
\end{tabular}

B. Blacks Residing in CPS Region with Treated State(s)

\begin{tabular}{|c|c|c|c|c|c|c|c|}
\hline Mean & 0.595 & 0.356 & 0.239 & 0.218 & 0.0572 & 0.130 & 0.257 \\
\hline \multicolumn{8}{|l|}{ Coefficient (se) on: } \\
\hline \multirow[t]{2}{*}{ Post-initiative share (population weighted) } & $0.219^{* * *}$ & $0.132^{* * *}$ & 0.087 & $-0.175^{* * *}$ & $-0.047 * * *$ & 0.003 & $-0.249 * * *$ \\
\hline & $(0.068)$ & $(0.040)$ & $(0.088)$ & $(0.049)$ & $(0.010)$ & $(0.049)$ & $(0.065)$ \\
\hline $\mathrm{N}$ & 176 & 176 & 176 & 176 & 176 & 176 & 126 \\
\hline $\begin{array}{l}p \text {-value: black }=\text { white coefficient } \\
\text { on post-initiative share }\end{array}$ & 0.133 & 0.714 & 0.288 & 0.953 & 0.0313 & 0.360 & 0.00702 \\
\hline Data Source & October CPS & October CPS & October CPS & October CPS & October CPS & October CPS & PSID \\
\hline Cohorts & $1963-78$ & $1963-78$ & $1963-78$ & $1963-78$ & $1963-78$ & $1963-78$ & $1963-78$ \\
\hline
\end{tabular}

Notes: Each entry in Panels A and B represents a different regression. Regressions in columns (1)-(6) are based on samples of five year olds from the October Current Population Survey. Regressions in column (7) are based retrospective questions on Head Start attendance asked of respondents to the Panel Study of Income Dynamics in 1995. Coefficient estimates are on the population-weighted fraction of the CPS region with kindergarten funding (see Appendix). The model is estimated on CPS regions containing any treated states and also includes as controls CPS region and cohort-by-education spending group of region and cohort-by-Southern Census division fixed effects. Means and regressions are weighted by the number of observations used to calcluate the dependent variable. Standard errors are clustered on CPS region (11 clusters). Critical values are drawn from a t-distribution with 9 degrees of freedom. $* * *, * *$, and $*$ indicate significance at the $1 \%, 5 \%$, and $10 \%$ levels, respectively. 
Table VI. Alternative Hypotheses: The Effects of State Kindergarten Funding on Federal Funding for Compensatory Early Education, School Revenues and School Programs, and Subsequent State Policies

\begin{tabular}{|c|c|c|c|c|}
\hline Dependent Variable & $\begin{array}{l}\text { Pre-initiative } \\
\text { Mean } \\
\text { (1) }\end{array}$ & $\begin{array}{l}\text { Coefficient on } \\
\text { Post-initiative } \\
\text { dummy (se) } \\
\text { (2) }\end{array}$ & $\begin{array}{l}\mathrm{N} \\
(3)\end{array}$ & $\begin{array}{l}\text { Sources and } \\
\text { Years } \\
(4)\end{array}$ \\
\hline & \multicolumn{4}{|c|}{ A. Federal Funding for Compensatory Education (\$2007) } \\
\hline \multicolumn{5}{|l|}{ Head Start: } \\
\hline $\ln$ (Outlay) & 17.15 & $\begin{array}{l}-0.060 \\
(0.053)\end{array}$ & 311 & a \\
\hline Outlay/4 Year Olds & 892.6 & $\begin{array}{l}-41.0 \\
(40.3)\end{array}$ & 299 & $a, b$ \\
\hline \multicolumn{5}{|l|}{ Title I ESEA: } \\
\hline $\ln$ (Outlay) & 18.36 & $\begin{array}{l}-0.020 \\
(0.033)\end{array}$ & 312 & a \\
\hline \multirow[t]{2}{*}{ Outlay/1st-12th Grade Enrollment } & 212.7 & $\begin{array}{l}-1.0 \\
(6.3)\end{array}$ & 312 & $\mathrm{a}, \mathrm{c}$ \\
\hline & \multicolumn{4}{|c|}{ B. Elementary and Secondary School Revenues (\$2007)/1st-12th Enr. } \\
\hline State & 1664 & $\begin{array}{l}99.4 \\
(113.4)\end{array}$ & 480 & $c, d$ \\
\hline Local/Intermediate/Other & 1505 & $\begin{array}{l}-47.7 \\
(138.3)\end{array}$ & 480 & $c, d$ \\
\hline Federal & 444.3 & $\begin{array}{l}23.2 \\
(25.2)\end{array}$ & 480 & $c, d$ \\
\hline Total & 3614 & $\begin{array}{l}75.3 \\
(117.0)\end{array}$ & 480 & $c, d$ \\
\hline \multirow{3}{*}{ Black-White Pupil-Teacher Ratio } & \multicolumn{4}{|c|}{ C. Pupil-Teacher Ratios } \\
\hline & 0.762 & $\begin{array}{l}-0.189 \\
(0.790)\end{array}$ & 154 & e \\
\hline & \multicolumn{4}{|c|}{ D. Other State Policies } \\
\hline $\begin{array}{l}\text { Birthday Cutoff for } 1 \text { st Grade Entry } \\
\qquad(+/- \text { Days from } 9 / 1 \text {, at age } 6)\end{array}$ & 62.8 & $\begin{array}{l}5.249 \\
(5.701)\end{array}$ & 406 & $\mathrm{f}$ \\
\hline $\begin{array}{l}\text { State-funded Pre-K Available } \\
\qquad(=1 \text { if true for cohort at age } 4)\end{array}$ & 0.0 & $\begin{array}{l}-0.00712 \\
(0.0112)\end{array}$ & 600 & g \\
\hline
\end{tabular}

Notes: Each entry in column (2) represents a different regression. Each regression also includes state fixed effects, year x education spending group of state fixed effects (see text), year x Southern region fixed effects, and indicators set to one if survey year is 7 or more years prior to or 7 or more years after the state initiative. The regressions in Panel D are conducted at the cohort level, with the birthday cutoff matched to a cohort based on that in effect at age six and the pre-kindergarten funding indicator matched to a cohort based on whether such funding existing when the cohort was age four. Samples include treated states only (Table I), and standard errors are clustered on state ( 24 clusters). Critical values are drawn from a t-distribution with 22 degrees of freedom. $* * *, * *$, and $*$ indicate significance at the $1 \%, 5 \%$, and $10 \%$ levels, respectively. 
Sources and Years (Years correspond to the academic years that begin in the years listed. See Appendix for more details):

a Federal outlays for Head Start (1967-83, not inc. 1968, 1980, and 1981) and Title I (1968-83, not inc. 1979-81): National Archives (1967-74, 1982-83) and ICPSR (1975-79)

b Estimated population of 4 Year Olds: live births in state 4 years prior as reported by Vital Statistics

c Enrollment in grades 1-12 (1959, 1961-83): CCD State Non-Fiscal Survey and and published tabulations of the Office of Education Surveys that preceded it

d Elementary and secondary school revenue by source: Statistics of State School Systems (1959, 1961), Digest of Educational Statistics (1963-83, not inc. 1964, 1972, and 1981)

e Race-specific pupil-teacher ratios: Card and Krueger (1992) (even years 1960-66), Office for Civil Rights school surveys (1967, even years 1968-72)

f Cutoff birthdates for 1st grade entry: Author's calculations from legislative histories of current state statutes and historical state session laws

g Dates of first funding for pre-kindergarten: Education Commission of the States (http://www.ecs.org) 
Appendix Table I. Kindergarten Funding and Family Background, by Race

\begin{tabular}{|c|c|c|c|c|c|c|c|c|c|c|}
\hline \multirow[b]{2}{*}{ Dependent variable: } & \multicolumn{4}{|c|}{ Maternal Characteristics: } & \multicolumn{6}{|c|}{ " Household Characteristics: } \\
\hline & $\begin{array}{l}\text { Average Age } \\
\text { (1) }\end{array}$ & $\begin{array}{l}\text { Average } \\
\text { Highest Grade } \\
\text { Completed } \\
\text { (2) } \\
\end{array}$ & $\begin{array}{l}\text { Share Head of } \\
\text { Household } \\
\text { (3) }\end{array}$ & $\begin{array}{l}\text { Average } \\
\text { Children Ever } \\
\text { Born } \\
(4) \\
\end{array}$ & $\begin{array}{l}\text { Share with no } \\
\text { Phone } \\
(5)\end{array}$ & $\begin{array}{l}\text { Share with no } \\
\text { Air } \\
\text { Conditioning } \\
(6)\end{array}$ & $\begin{array}{l}\text { Share with no } \\
\text { Car } \\
(7)\end{array}$ & $\begin{array}{l}\text { Share with No } \\
\text { Indoor } \\
\text { Plumbing } \\
(8)\end{array}$ & $\begin{array}{l}\text { Average Rooms } \\
\text { per Person } \\
(9)\end{array}$ & $\begin{array}{l}\text { Share with } \\
\text { Rooms } \\
\text { Topcoded } \\
(10)\end{array}$ \\
\hline & \multicolumn{10}{|c|}{ A. Whites Born in States with Kindergarten Funding Initiatives } \\
\hline Pre-initiative mean & 30.05 & 10.81 & 0.0644 & 3.221 & 0.269 & 0.690 & 0.0778 & 0.130 & 1.099 & 0.0292 \\
\hline Post-initiative dummy & $\begin{array}{l}-0.066 \\
(0.075)\end{array}$ & $\begin{array}{l}0.059 * * * \\
(0.021)\end{array}$ & $\begin{array}{l}-0.0007 \\
(0.0035)\end{array}$ & $\begin{array}{l}-0.013 \\
(0.026)\end{array}$ & $\begin{array}{l}-0.0092 \\
(0.0061)\end{array}$ & $\begin{array}{l}0.0034 \\
(0.0070)\end{array}$ & $\begin{array}{l}0.0025 \\
(0.0030)\end{array}$ & $\begin{array}{c}-0.0015 \\
(0.0054)\end{array}$ & $\begin{array}{l}0.0007 \\
(0.0047)\end{array}$ & $\begin{array}{l}-0.0009 \\
(0.0035)\end{array}$ \\
\hline Linear trend in normalized year & $\begin{array}{l}0.004 \\
(0.027)\end{array}$ & $\begin{array}{l}-0.011 \\
(0.012)\end{array}$ & $\begin{array}{l}0.0001 \\
(0.0009)\end{array}$ & $\begin{array}{l}0.004 \\
(0.014)\end{array}$ & $\begin{array}{l}0.0030 \\
(0.0027)\end{array}$ & $\begin{array}{l}0.0034 \\
(0.0056)\end{array}$ & $\begin{array}{l}-0.0017 \\
(0.0018)\end{array}$ & $\begin{array}{l}0.0025 \\
(0.0024)\end{array}$ & $\begin{array}{l}-0.0024 \\
(0.0020)\end{array}$ & $\begin{array}{l}0.0007 \\
(0.0009)\end{array}$ \\
\hline Post-initiative trend break & $\begin{array}{l}-0.038 \\
(0.024)\end{array}$ & $\begin{array}{l}0.010 \\
(0.013)\end{array}$ & $\begin{array}{l}-0.0008 \\
(0.0010)\end{array}$ & $\begin{array}{l}-0.000 \\
(0.011)\end{array}$ & $\begin{array}{l}-0.0049 * \\
(0.0025)\end{array}$ & $\begin{array}{l}-0.0010 \\
(0.0041)\end{array}$ & $\begin{array}{l}-0.0006 \\
(0.0009)\end{array}$ & $\begin{array}{l}-0.0010 \\
(0.0031)\end{array}$ & $\begin{array}{l}-0.0000 \\
(0.0025)\end{array}$ & $\begin{array}{l}-0.0020^{* *} \\
(0.0009)\end{array}$ \\
\hline R-squared & 0.99 & 0.97 & 0.87 & 0.97 & 0.96 & 0.97 & 0.80 & 0.93 & 0.99 & 0.88 \\
\hline $\mathrm{N}^{1}$ & 840 & 840 & 840 & 840 & 840 & 840 & 840 & 840 & 840 & 840 \\
\hline Pre-initiative mean & 30.57 & 9.244 & 0.264 & 4.937 & 0.592 & 0.905 & 0.440 & 0.442 & 0.772 & 0.0102 \\
\hline \multicolumn{11}{|l|}{ Coefficient (standard error) on: } \\
\hline Post-initiative dummy & $\begin{array}{l}-0.352 \\
(0.243)\end{array}$ & $\begin{array}{l}0.077 \\
(0.065)\end{array}$ & $\begin{array}{l}-0.0015 \\
(0.0093)\end{array}$ & $\begin{array}{l}-0.159 * * \\
(0.076)\end{array}$ & $\begin{array}{c}-0.0066 \\
(0.0100)\end{array}$ & $\begin{array}{l}-0.0001 \\
(0.0070)\end{array}$ & $\begin{array}{l}-0.0121 \\
(0.0107)\end{array}$ & $\begin{array}{l}-0.0031 \\
(0.0060)\end{array}$ & $\begin{array}{c}-0.0108 \\
(0.0073)\end{array}$ & $\begin{array}{l}0.0015 \\
(0.0036)\end{array}$ \\
\hline Linear trend in normalized year & $\begin{array}{l}0.005 \\
(0.043)\end{array}$ & $\begin{array}{l}-0.011 \\
(0.016)\end{array}$ & $\begin{array}{l}0.0004 \\
(0.0031)\end{array}$ & $\begin{array}{l}0.031 \\
(0.020)\end{array}$ & $\begin{array}{l}-0.0019 \\
(0.0047)\end{array}$ & $\begin{array}{l}0.0029 \\
(0.0049)\end{array}$ & $\begin{array}{l}-0.0029 \\
(0.0023)\end{array}$ & $\begin{array}{l}0.0035 \\
(0.0030)\end{array}$ & $\begin{array}{l}0.0043^{*} \\
(0.0022)\end{array}$ & $\begin{array}{l}-0.0003 \\
(0.0010)\end{array}$ \\
\hline Post-initiative trend break & $\begin{array}{l}0.020 \\
(0.083)\end{array}$ & $\begin{array}{l}0.004 \\
(0.022)\end{array}$ & $\begin{array}{l}-0.0029 \\
(0.0034)\end{array}$ & $\begin{array}{l}-0.018 \\
(0.023)\end{array}$ & $\begin{array}{l}0.0017 \\
(0.0039)\end{array}$ & $\begin{array}{l}-0.0034 \\
(0.0036)\end{array}$ & $\begin{array}{l}0.0074 * \\
(0.0039)\end{array}$ & $\begin{array}{l}0.0039 \\
(0.0068)\end{array}$ & $\begin{array}{l}-0.0046 \\
(0.0029)\end{array}$ & $\begin{array}{l}-0.0012 \\
(0.0010)\end{array}$ \\
\hline R-squared & 0.94 & 0.96 & 0.91 & 0.96 & 0.97 & 0.95 & 0.87 & 0.97 & 0.97 & 0.65 \\
\hline $\mathrm{N}$ & 753 & 753 & 753 & 753 & 760 & 739 & 748 & 760 & 760 & 760 \\
\hline
\end{tabular}

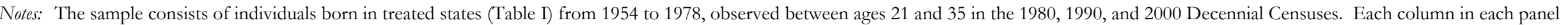

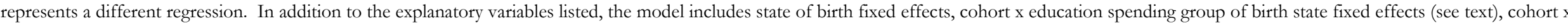

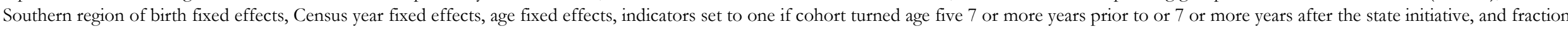

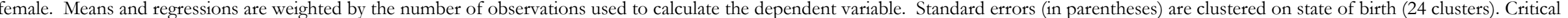
values are drawn from a t-distribution with 22 degrees of freedom. ${ }^{* *}, * *$, and $*$ indicate significance at the $1 \%, 5 \%$, and $10 \%$ levels, respectively. 
Figure I. Public School Kindergarten Enrollment and Supply by Region

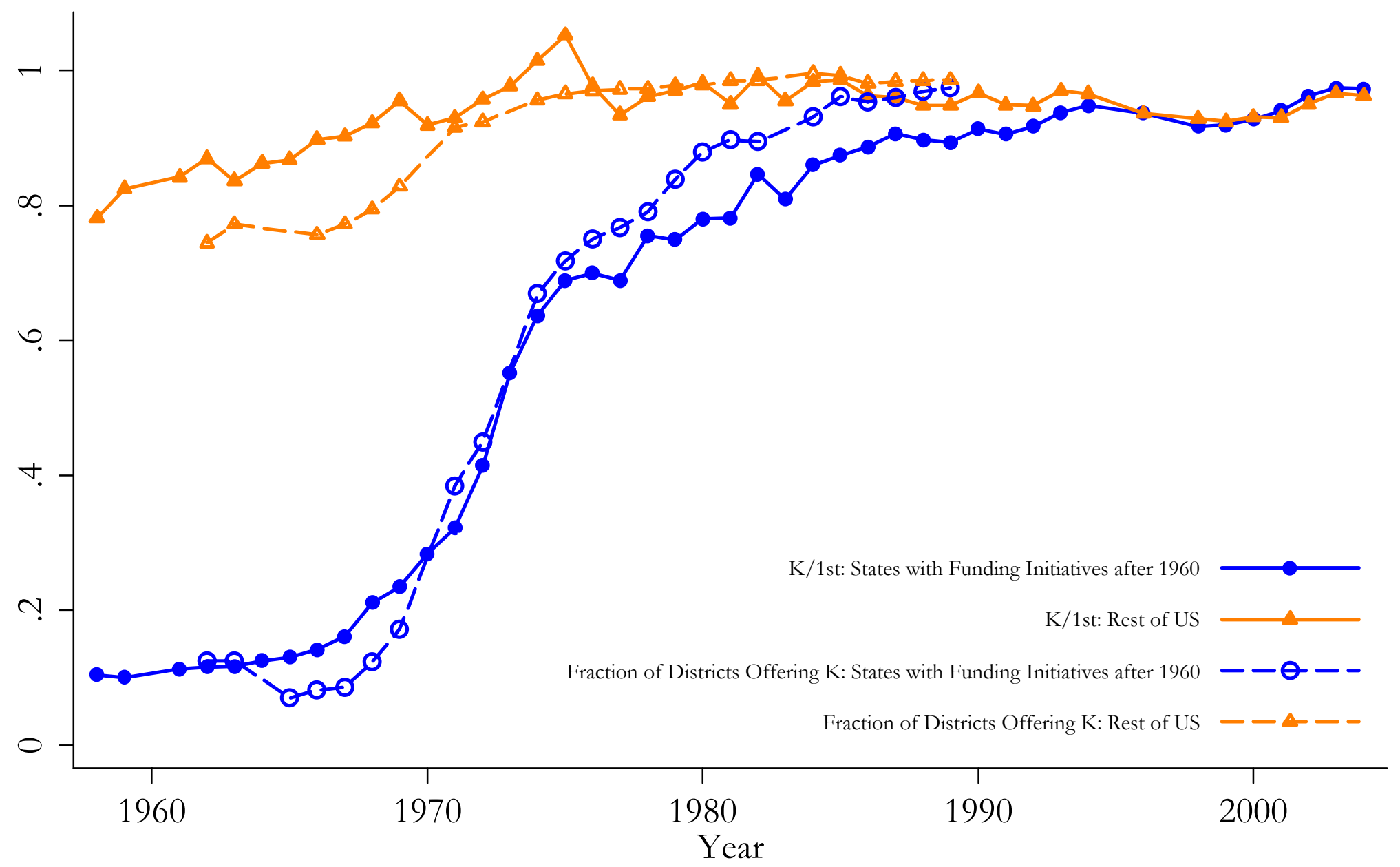

Notes: States with funding initiatives after 1960 (treated states) are listed in Table I. The solid lines give trends in the ratio of aggregate kindergarten enrollment to aggregate first grade enrollment, separately for treated states and the rest of the United States. The dashed lines give trends in the ratio of the aggregate number of school districts with kindergarten to the aggregate number of school districts serving primary grades, separately for treated states and the rest of the United States; data for 1962 and 1963 pertain only to districts with 300 or more students enrolled. Sources: Data on kindergarten and first grade enrollment were drawn from Common Core of Data (CCD) State Non-Fiscal Survey and published tabulations of the Office of Education Surveys that preceded it. Data used to calculate the fraction of districts with kindergarten were drawn from Education Directory, Elementary and Secondary General Information Survey, and the CCD Local Education Agency Surveys. See Appendix for more details. 


\section{Figure II. State Kindergarten Funding and Kindergarten Supply and Enrollment}
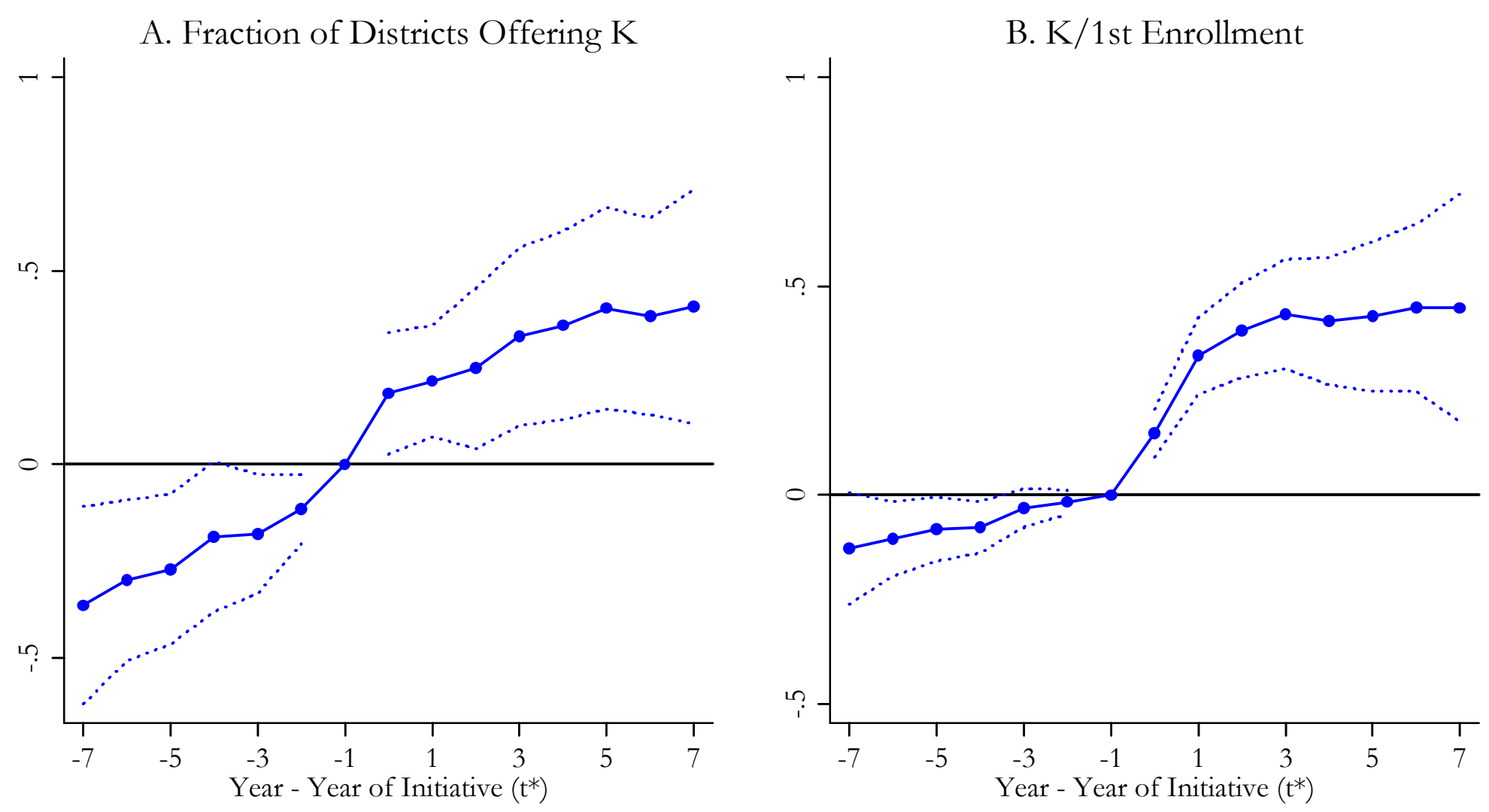

Notes: Solid lines connect coefficients on dummies for year of observation - year of state funding initiative from estimation of equation (1). Dashed lines connect the 95 percent confidence bounds on the estimates; standard errors are clustered on state. Underlying regressions give each state equal weight, and include as controls fixed effects for state, year x education spending group of state (see text), and year x Southern region. Underlying data span fall 1962 to fall 1982 (not including 1964, 1970, and 1973) in Panel A and fall 1959 to fall 1983 (not including 1960) in Panel B. See notes to Figure I and Appendix for description of sources. 


\section{Figure III. State Kindergarten Funding and Schooling Outcomes, by Race}

\section{A. Whites}
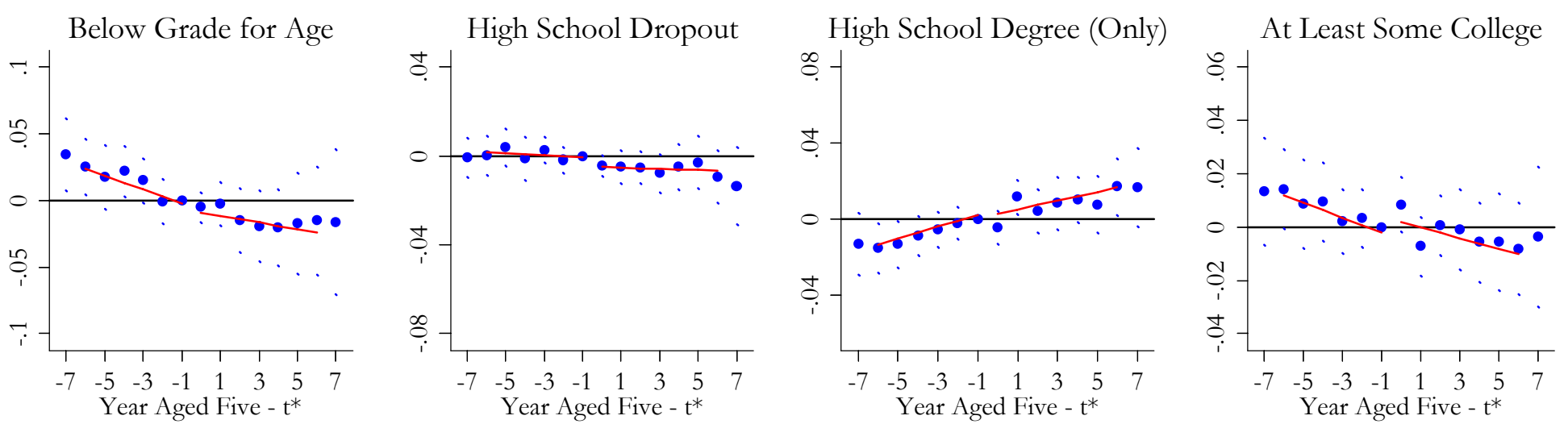

\section{B. Blacks}
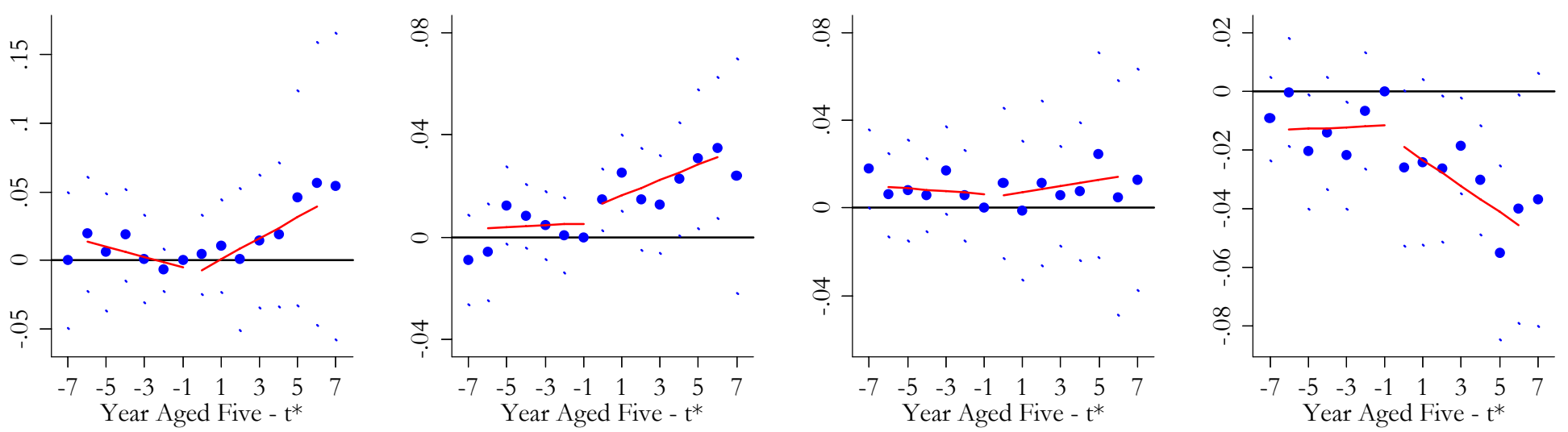

Notes: The large dots represent coefficients on dummies for year aged five - year of state funding initiative from estimation of equation (1). The small dots represent 95 percent confidence intervals on these estimates; standard errors are clustered on state of birth. The solid lines represent regression fits from estimation of equation (3). Regression specifications correspond to those presented in Table III and thus include as controls the fraction female in the birth statecohort-Census year cell and fixed effects for birth state, age, Census year, cohort x education spending group of birth state (see text), and cohort x Southern region of birth. Regressions are also weighted by the number of observations used to construct the birth state-cohort-Census year average. See notes to Table III for description of sources and samples. 


\section{Figure IV. State Kindergarten Funding and Employment}

and Earnings Outcomes, by Race

A. Whites
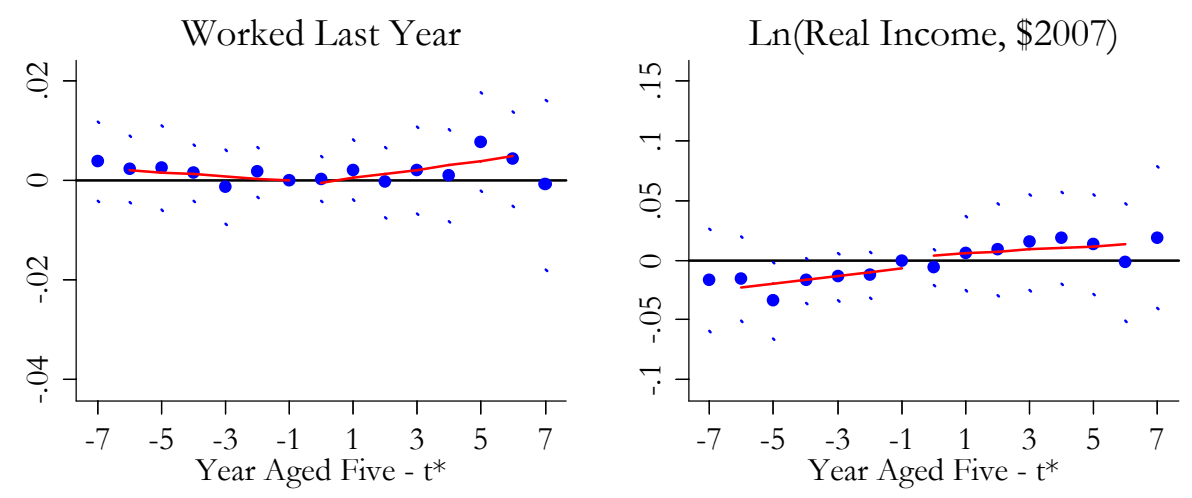

B. Blacks
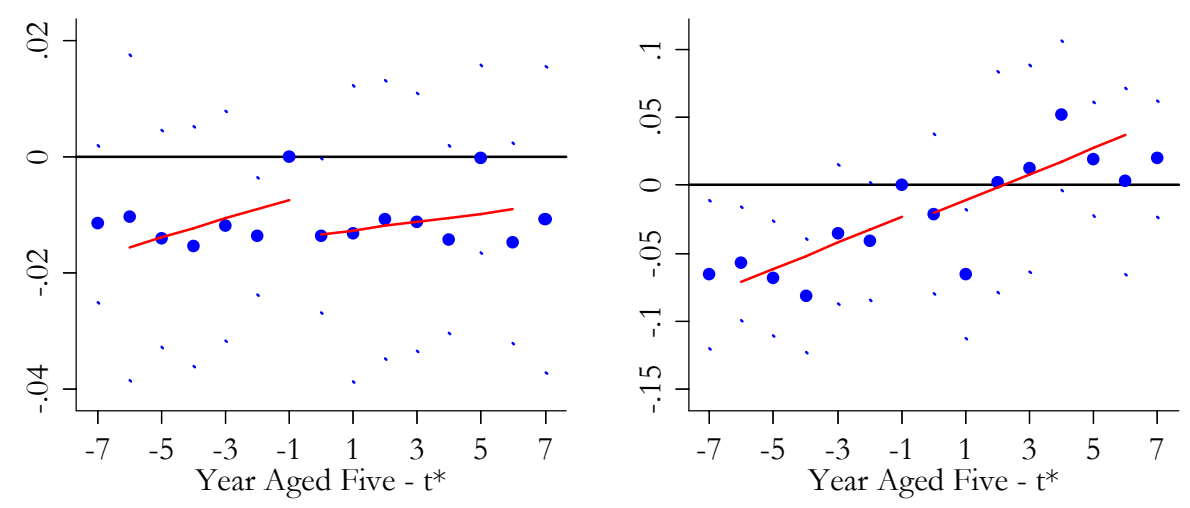

Notes: See notes to Figure III. 
Figure V. State Kindergarten Funding and Public Assistance Receipt, Institutionalization, and Health, by Race

A. Whites
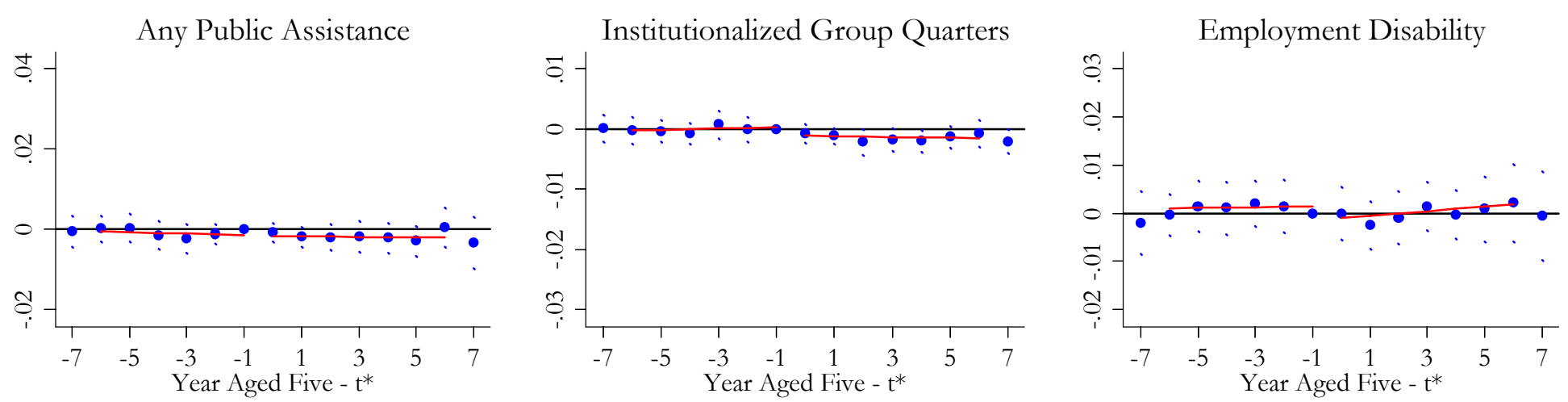

B. Blacks
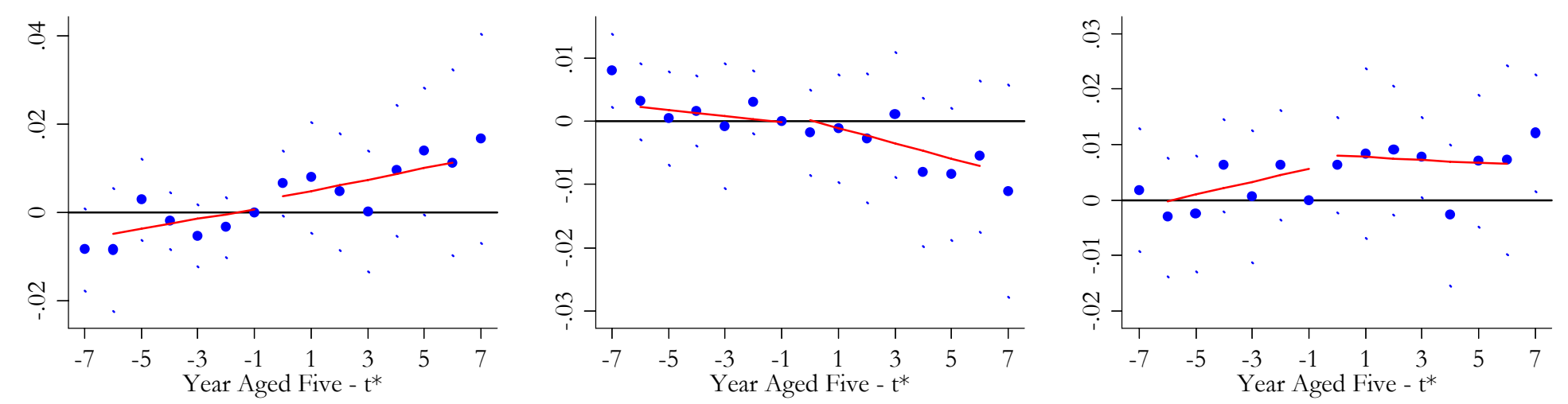

Notes: See notes to Figure III. 


\section{Figure VI. State Kindergarten Funding and Federal Funding for Compensatory Education}

A. Head Start $(\$ 2007)$
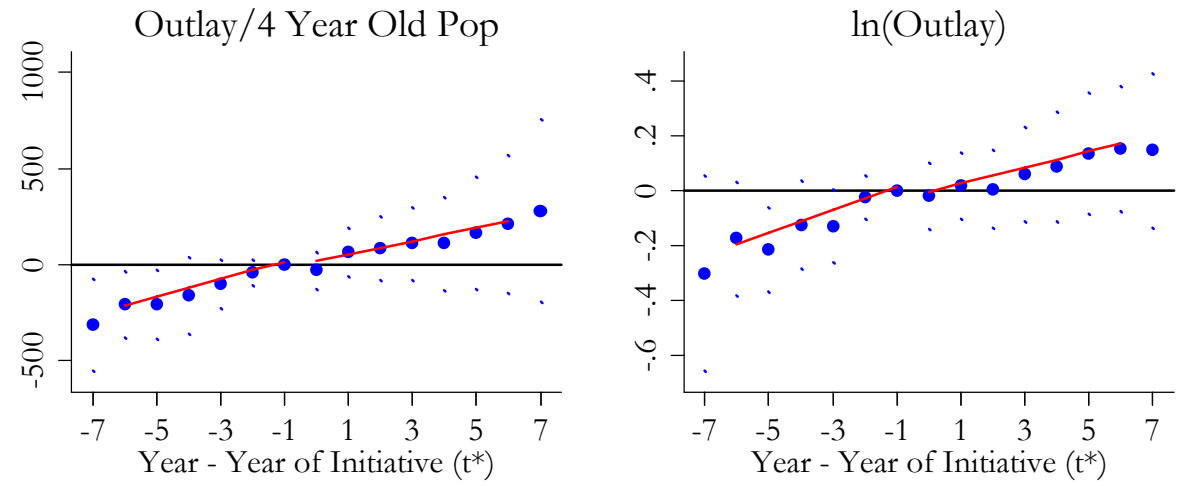

\section{B. Title I ESEA (\$2007)}
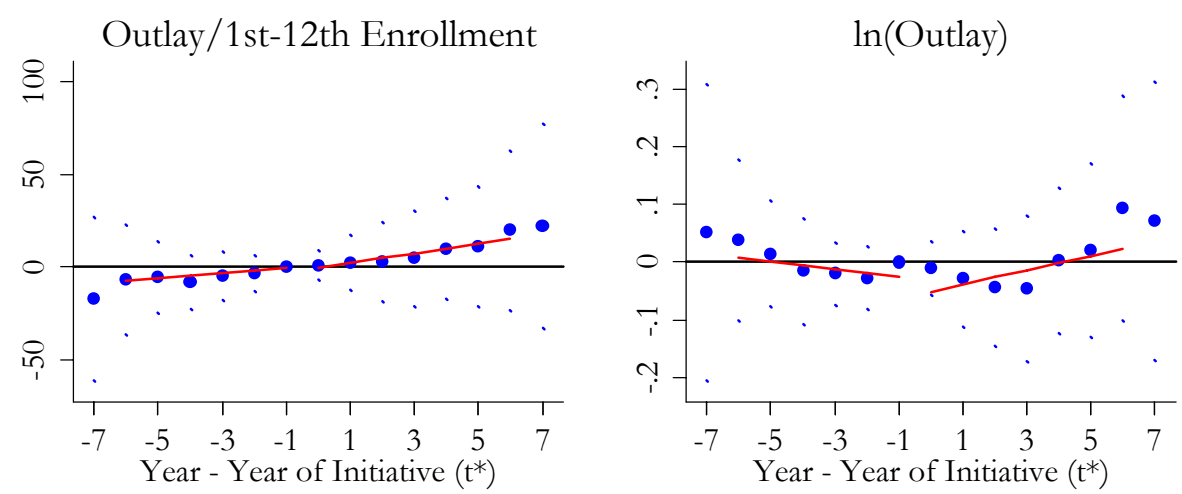

Notes: The large dots represent coefficients on dummies for year of observation - year of state funding initiative. The small dots represent 95 percent confidence intervals on these estimates; standard errors are clustered on state. The solid lines represent regression fits from estimation of equation (3). Regression specifications correspond to those presented in Table VI and thus include as controls fixed effects for state, year x education spending group of state (see text), and year x Southern region. Underlying data span 1967-83. See notes to Table VI and the Appendix for description of sources. 


\section{Appendix Figure I. Year of State Kindergarten Funding and Education Expenditure per Pupil, 1964-65}

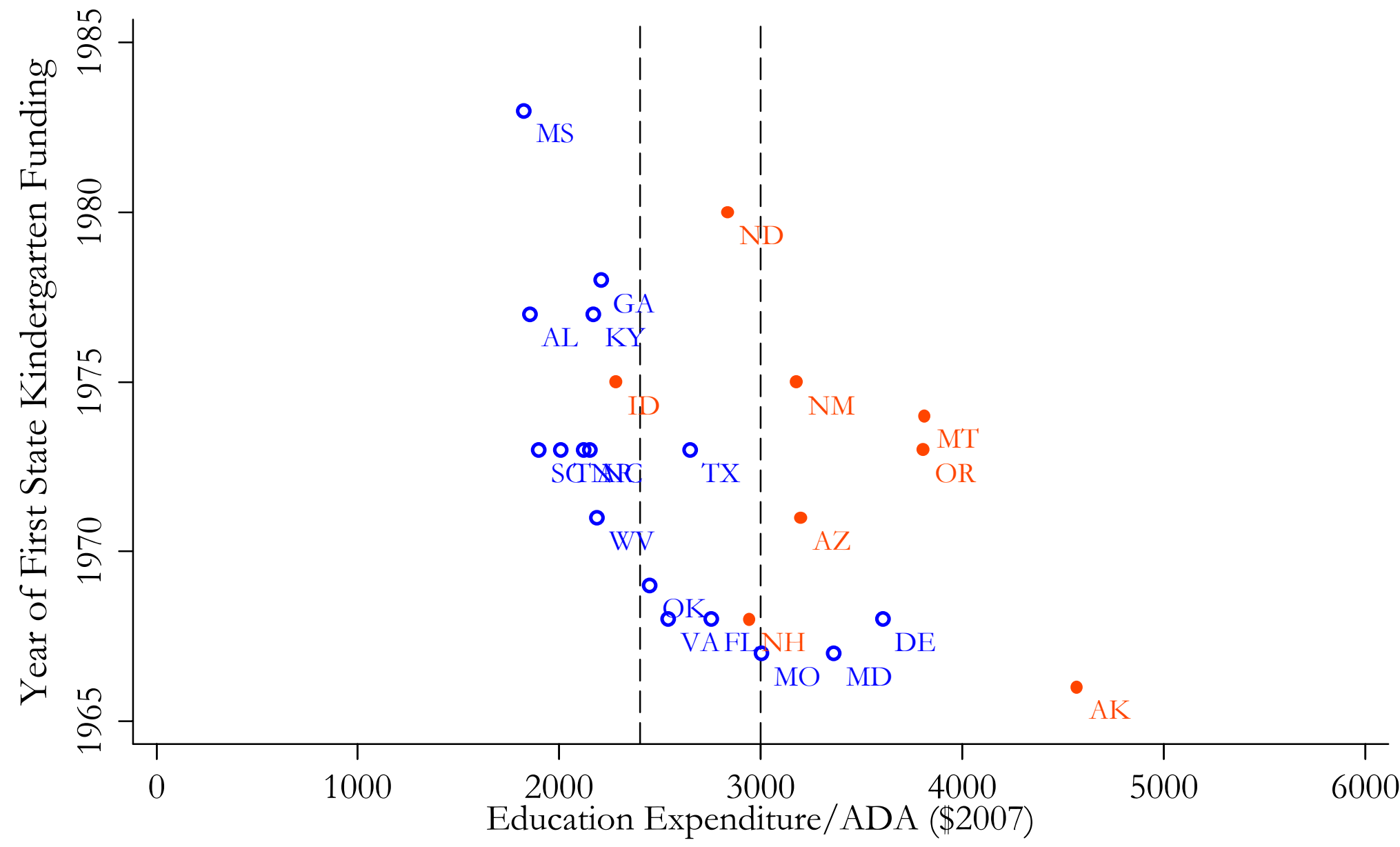

Notes: Hollow circles represent states in the South. Solid circles represent states elsewhere in the country. The dashed lines represent divisions between three groups of states based on pre-initiative spending on education; groups were defined so as to create roughly equal ranges on expenditure/ADA for states in the South. Indicators for these groups are interacted with indicators for year (aged five) in the main empirical specification. See Appendix for description of data sources. 


\section{Appendix Figure II. Placebo Initiatives and Selected Outcomes, by Race}

\section{A. Whites}
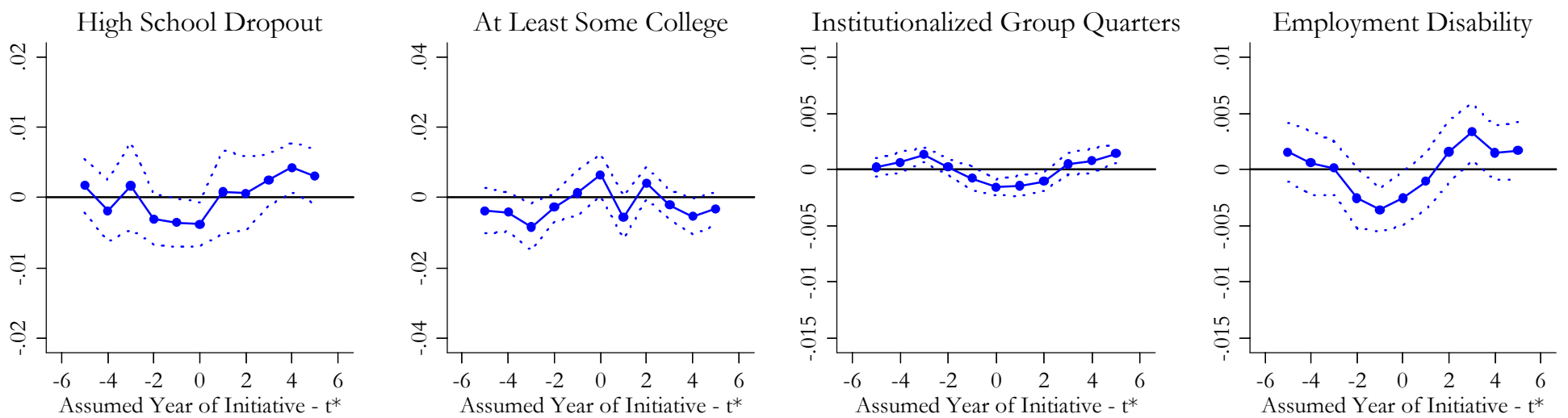

B. Blacks
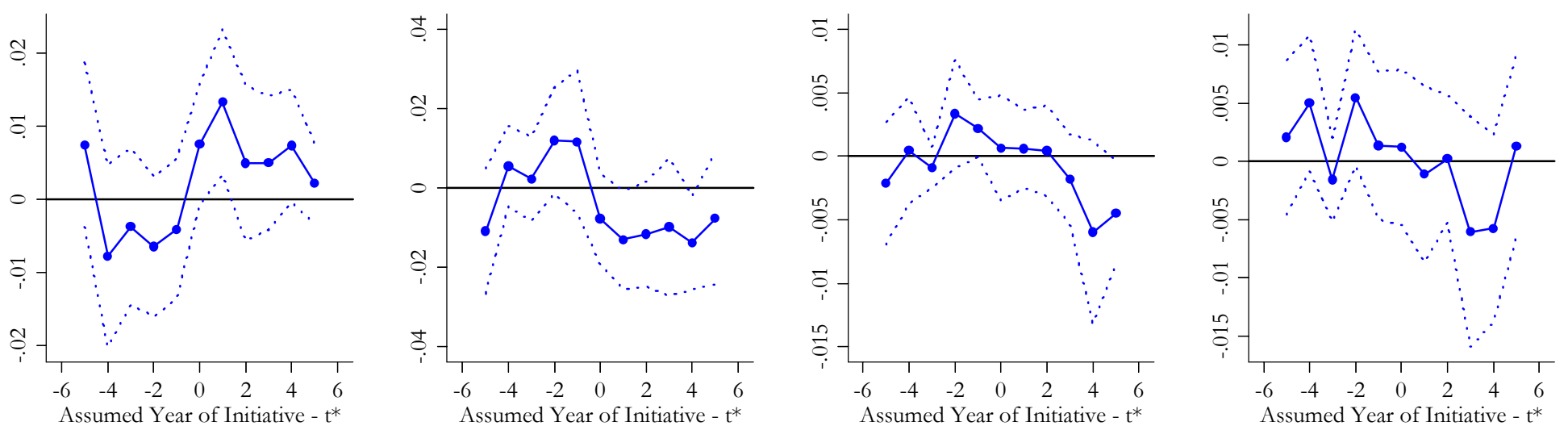

Notes: Solid lines connect estimates of the coefficient on the post-initiative indicator from a version of equation (3) where the initiative is assumed to have been passed in year $j=t-t^{*}$, where $t^{*}$ represents the actual year of passage and $-5 \leq j \leq 5$. Dashed lines connect the 90 percent confidence bounds on the estimates; standard errors are clustered on state. See notes to Table III and the Appendix for description of data sources and samples. 


\section{Appendix Figure III. Placebo Initiatives and Kindergarten Supply and Enrollment}
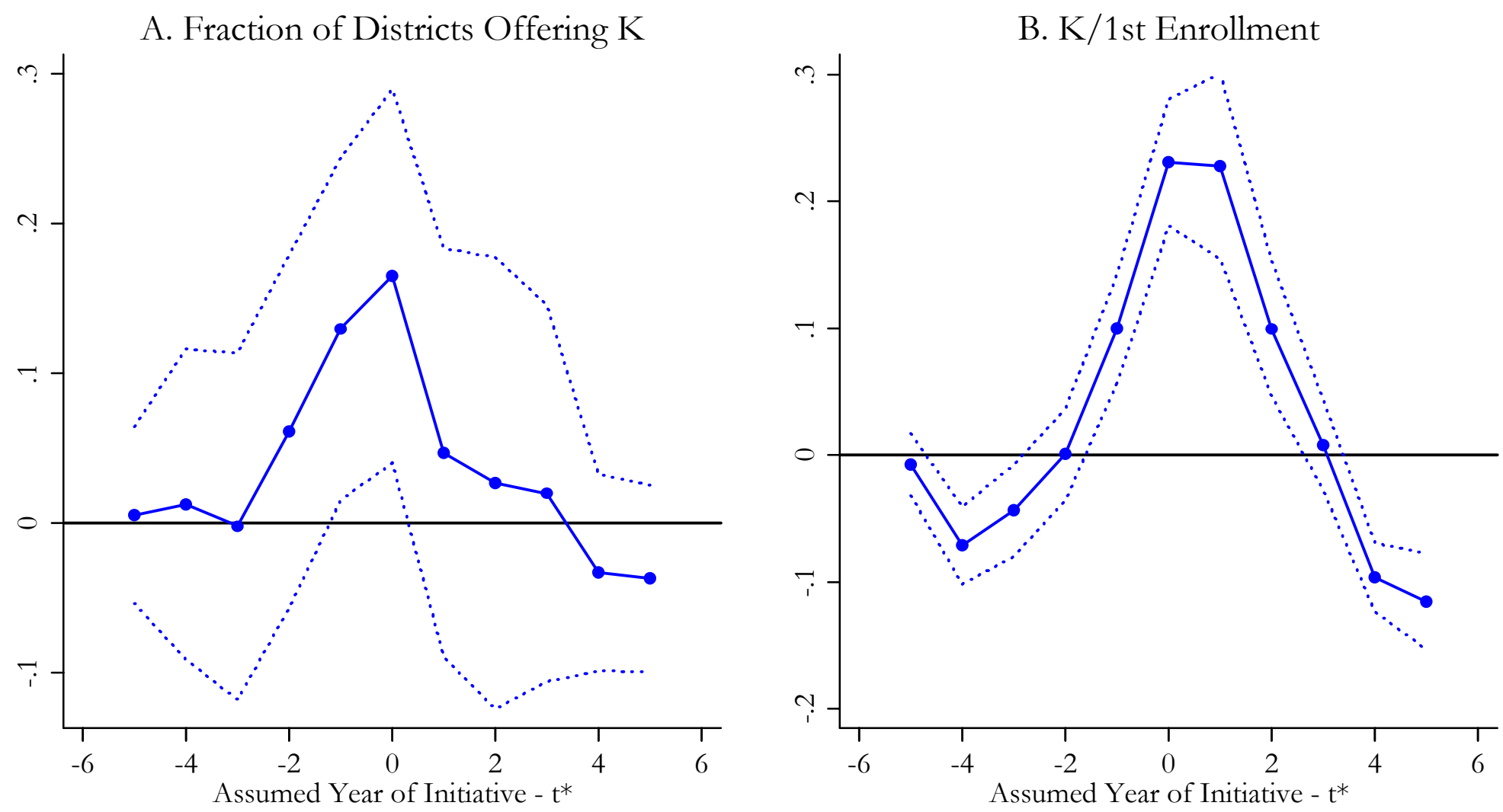

Notes: See notes to Appendix Figure II. See notes to Table II and the Appendix for description of sources and samples. 